\title{
Artırılmıș Gerçeklik Teknolojisi Üzerine Yapılan Akademik Çalışmaların İçerik Analizi
}

\author{
Tarık İÇTEN ${ }^{1}$, Güngör BAL ${ }^{2}$ \\ ${ }^{1}$ Bilișim Sistemleri Bölümü, Bilișịm Enstitüsü, Gazi Üniversitesi, Ankara, Türkiye \\ ${ }^{2}$ Elektrik-Elektronik Mühendisliği Bölümü, Teknoloji Fakültesi, Gazi Üniversitesi, Ankara, Türkiye \\ ictentarik@gmail.com, gungorbal@gmail.com \\ (Geliş/Received:06.02.2017; Kabul/Accepted:03.09.2017) \\ DOI: $10.17671 /$ gazibtd.290253
}

\begin{abstract}
Özet-Bu çalışmanın amacı akademik düzeydeki artırılmış gerçeklik çalışmalarının sahip olduğu yazılımsal ve donanımsal özellikleri de kapsayacak şekilde incelemek ve eğilimlerini ortaya çıkarmaktır. Bu amaçla, 2010-2016 yılları arasında uluslararası ve ulusal 27 dergide yayınlanmış artırılmış gerçeklik ile ilgili 34 akademik çalı̧ma içerik analiz yöntemiyle incelenmiştir. İncelemelerde araştırmacılar tarafından geliştirilmiş olan veri toplama ölçeği ile verilerin toplanması sağlanmıştır. Çalışmaların; yayın yıllarına, yayınlandığı dergi veya kitaplara, artırılmış gerçeklik(AG) işaretçi kullanım türüne, görüntüleme sistem türüne, uzamsal görüntüleme sistemleri dağılımına, taşınabilir görüntüleme sistemleri dağılımına, başa monte edilen görüntüleme sistemleri dağılımına (HMD), kullanıc1 ve cihaz etkileşim yöntemine, kullanılan artırılmış gerçeklik araçlarına (fireworks) göre dağılımlarına bakılmıştır. 9 kategoride taraması yapılmıș çalıșmaların eğilimleri betimsel istatistiksel yöntemlerle çözümlenmiş ve yorumlanmıștır. Elde edilen verilerin analizi sonucunda; 2010-2016 yılları arasında AG alanında yapılan çalışma sayılarının yakın olduğu, en fazla çalışmanın IEEE'de yayınlandığı $(\% 17,6)$, araştırmacılar tarafından çalışmalarda çoğunlukla işaretçi tabanlı AG teknolojisinin $(\% 82,3)$ kullanıldığı, video tabanlı sistemlerin $(\% 94,1)$ optik tabanlı sistemlere $(\% 5,9)$ göre daha fazla tercih edildiği, kullanıcı-uygulama etkileșiminin ağırlıklı dokunma veya fare ile yapıldı̆̆ı, ortam oluşturmada ARToolKit aracının (\%41,1) daha fazla tercih edildiği belirlenmiş̧ir. Çalışmadan elde edilen sonuçların gelecek çalışmalara 1şık tutacağı düşünülmektedir.
\end{abstract}

Anahtar Kelimeler - Artırılmış gerçeklik, artırılmış gerçeklik ortamı, artırılmış gerçeklik uygulamaları, içerik analizi

\section{A Content Analysis of the Academic Works on the Augmented Reality Technology}

\begin{abstract}
Purpose of this study was to examine the software and hardware features of the augmented reality works at the academic level. In accordance with the purpose, 34 academic studies on augmented reality published between the years of 2010 and 2016 in 27 national and international journals were analyzed via content analysis method. Data collection scale developed by the researchers provided data collection. Specifically, these studies are investigated in terms of the year of publication; the research journal or book, the AR type usage, the AR imaging systems, the spatial imaging systems, the distribution of portable imaging systems, the Head-mounted imaging systems, the AR Workinguser interaction distribution, the distribution of AR tools. The trends of the studies examined in 9 categories have been analyzed and interpreted by descriptive statistical methods. As a result of the research, numbers of AR studies published between 2010 and 2016 are close to each other, most studies were published by the IEEE, a marker-based augmented reality technology has been used in most studies, video-based systems are used more than optical-based systems, many studies achieved with the touch or mouse/keyboard in the application, ARToolKit tools were more preferred. The results obtained by this study will be helpful for directing the future studies.
\end{abstract}

Keywords - Augmented reality, augmented reality technology, augmented reality applications, content analysis

\section{GİRISS (INTRODUCTION)}

Son yıllarda bilişim teknolojileri alanında en çok dikkat çeken çalışmalardan birisi de Artırılmış Gerçeklik (AG) olarak ifade edilen Augmented Reality (AR) teknolojisidir. Artırılmış gerçeklik birçok alanda çalışmanın yapıldığı, gün geçtikçe günlük hayatımızda daha fazla yer almaya başlamış bir teknolojidir [1]. 
Milgram ve Kishino (1994) [2] Gerçeklik-Sanallık Sürekliliği (şekil 1) adını verdikleri teori düzleminde sanal gerçeklik (virtual reality), artırılmış gerçeklik (augmented reality) ve karıștırılmış gerçeklik (mixed reality) kavramlarını ifade etmişlerdir. Bu kavramlardan sanal gerçeklik, bilgisayar kaynaklı üç boyutlu oyunlarda karşılaşılan, kullanıcının bu ortama girdiğinde dünya ile ilişkisinin tamamen yok olduğu bir ortam olarak söylenebilir. Artırılmış gerçeklik ise gerçek dünya ile bağlantısını devam ettiren, veri ve görüntülerin gerçek dünya görüntülerine eklenebildiği, gerçek ve sanal nesnelerin aynı ortamda birlikte algılanmasını sağlayan bir ortam olarak ifade edilebilir [1].

Artırılmış gerçeklik ve sanal gerçeklik kavramları birbiriyle karıştırılabilmektedir [3]. Bilgisayar tarafından oluşturulmuş sanal gerçeklik ve artırılmış gerçeklik kavramları benzer öğeleri kullanan ancak gerçek ve sanal dünya arasında birbirinden farklı kavramlar olarak görülmektedir [4]. Sanal gerçeklik sanal dünyayı temel alırken, artırılmıș gerçeklik gerçek dünyayı temel almaktadır. Azuma'ya (1997) [5] göre artırılmıș gerçeklik sanal ortamların veya sanal gerçekliğin bir varyasyonudur. Artırılmış gerçekliğin gelişim sürecince sanal ve gerçek ilişkisini anlatan birçok ifade kullanılmıştır. Şekil 1'de, sanal ve gerçek ilişkisini gösteren teori düzlemi bu konu hakkındaki tanımları daha da anlaşılır hale getirecektir [1].

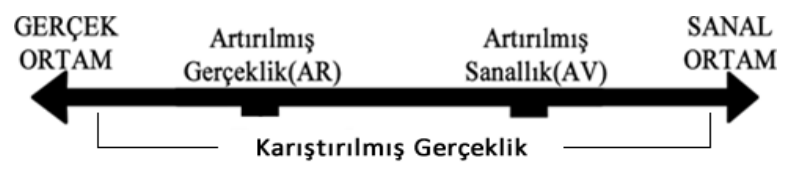

Şekil 1. Milgram’ın gerçeklik-sanallık sürekliliği (Milgram's reality-virtuality continuum)

Artırılmış gerçeklik, kullanılan teknoloji dikkate alındığında optik temelli teknolojiler ve video temelli teknolojiler [5] olarak iki grupta değerlendirilebilir. Optik ve video temelli teknolojiler arasındaki temel fark gerçek ve sanal dünyanın bütünleştirilmesiyle oluşan sahnenin görüldüğü yerdir. Optik sistemlerde bütünleştirilmiş sahne gözlük aracılığıyla gerçek dünyada görülürken, video temelli sistemlerde bütünleştirilmiş sahne bilgisayar/tablet/mobil cihaz üzerinde görülmektedir [3].

Görüntüleri ses, grafik, animasyon gibi bilgilerle artırma teknolojisi uzun süredir gündemde olan bir teknolojidir. Bilişim teknolojilerindeki hızlı değişim ve mobil teknolojilerin kullanım oranındaki artış ile birlikte görsel teknoloji içerikleri de önem kazanmaktadır [6]. Bu görsel teknoloji içeriklerinin kullanıcılar tarafından tercih edilmesi bu teknolojinin kullanıldığı donanım cihazlarının da gelişmesine sebep olacaktır. Zamanla AG pazarında PC, akıllı telefon ve tablet gibi teknolojik ürünlerin daha fazla yer alacağı, bu ürünlerin daha etkin bir şekilde günlük hayatımızdaki uygulamalarda kullanılacağı tahmin edilmektedir.

\section{ARTIRILMIŞ GERÇEKLİK(AUGMENTED REALITY)}

Artırılmış gerçeklik teknolojisi alanında yapılan çalışmaların sayısı son yıllarda artmaktadır. Bu çalışmalar 1şığında bu alanda yapılan tanım ve terimler teknolojideki gelişmelere bağlı olarak değișkenlik göstermektedir. Alanyazın incelendiğinde Milgram ve Kishino (1994) [2] artırılmış gerçekliği "Gerçek dünya nesneleri yerine dijital ortam ürünlerinin kullanıldığı gerçeklik ortamıdır.’'[7] şeklinde tanımlamıştır. Azuma'ya (1997) [5] göre ise sanal ile gerçeğin eş zamanlı ve içi içe girdiği etkileşimli bir teknoloji ortamlardır. Özarslan (2011) çalışmasında artırılmış gerçekliği; "Bir kamera ya da görüntüleme cihazı aracılığıyla çoğunlukla gömülü bir hedefi okuyup sanal olarak bilgisayarda üretilen görüntü ve gerçek dünyanın görüntüsünün yazılımsal olarak bir araya getirilmesiyle oluşmaktadır." [8] şeklinde tanımlamaktadır. Gonzato, Arcila ve Crespin'nun (2008) [9] yapmış olduğu tanımlamaya göre gerçek dünya görüntüleri üzerine metin, ses, resim gibi ek bilgilerin eklenmesi ile canlı görüntünün bir parçasıymış hissini verdiren teknolojidir. Sanal ve gerçek dünya arasındaki etkileşimli ortamı artırılmış gerçeklik oluşturur. Bunun sağlanması için artırılmış gerçeklik kullanılır [10-11]. Artırılmış gerçeklik ortamlarında sanal ve gerçek nesneler birleștirilerek kullanıcılara uyum içerisinde sunulmaktadır. Bir başka ifadeyle artırılmış gerçeklik, gerçek dünyanın etkilenmesine neden olmadan, kullanıcıların gerçek dünya ile etkileşim halindeyken sanal nesnelerle de etkileşime girdiği bir sanal gerçeklik uygulamasıdır [12]. Feiner'a göre (2002) [13] çeşitli uygulama programları sayesinde gerçek ile sanalın eş zamanlı olarak gerçek dünya üzerinde birleşmesidir. Van Krevelen \& Poelman'nın (2010) [14] yapmış olduğu tanımda ise artırılmış gerçeklik gerçek görüntü ile sanal görüntünün aynı anda zenginleştirilmesi ile oluşan bir yapıdır. Bu özellikleri dikkate alındığında Sırakaya ve Seferoğlu, (2016) [15] artırılmış gerçekliği gerçek dünya ortamına sanal nesnelerin eklenmesiyle oluşturulan eş zamanlı karma gerçeklik ortamı olarak tanımlar. Bu tanımlamalardan anlaşılacağı gibi artırılmış gerçekliğin temelini gerçek durum üzerine bindirilen sanal verilerle zenginleştirme [16-17] işlemi olduğu anlaşılmaktadır.

AG'nin tarihsel gelişimi incelendiğinde, ilk olarak Prof. Caudell [18] başa monte edilen bir dijital görüntüleme sistemi kullanımı ile uçaklara elektrik kablolarının düzgün bir şekilde yerleştirilmesi sürecinde AG'yi kullanmıştır. 1993'de L.B Rosenberg (1993) [19] Sanal Aparatlar (Virtual Fixture) adi verilen AG sistemi geliştirmiştir. Bu çalışmada sistemin ürün kullanımındaki etkinliği ve kullanıcıya olan faydaları açıklanmıştır. 1993 y1linda ise Feiner, Macintyre ve Seligann (1993) [20] tarafindan KARMA (Knowledge-based Augmented Reality for Maintenance Assistance) adı verilen bir AG sistem prototipi tanıtımı yapılmıştır. 1997 yılında ise Azuma (1995) AG üzerine yazılım çalışmaları yapmıştır [5]. Bir sene sonra Ramesh Raskar, Greg Welch ve Henry Funchs (1998) [21] tarafından "uzamsal artırılmış gerçeklik” yapısı oluşturulmuştur. 1999’da Dr. Hirokazu 
Kato tarafından ARToolKit (Augmented Reality Tool Kit) [22] adı verilen AG tabanlı bir yazılım kütüphanesi geliştirilmiştir. 2000'de ise Bruce Thomas (2000) [23] tarafindan ilk mobil AG oyunu "ARQuake" geliştirilmiştir. 2012 yılına gelindiğinde ise Google firması X Laboratuvarında geliştirmiş olduğu ilk AG gözlüğü "Project Glass" cihazını üretmiştir [24]. 2013 y1lında otomobil üreticileri (Volkswagen) yeniçağın araç servis asistanı (MARTA-Mobile Augmented Reality Technical Assistance) olarak AG'yi kullanmaya başlamışlardır. 2014 yılına gelindiğinde Google, tüketiciler için giyilebilir özellikli Google Glass cihazının sevkiyatına başlamıştır. Microsoft, 2015 yılında HoloLens projesi olan akıllı giyilebilir AG gözlüğünü tanıtmış, 2016 yılında ise geliştirme sürümünü piyasaya çıkarmıştır.

Artırılmış gerçekliğin etkin, ilgi çekici ve görsel zenginliği bu teknolojiyi birçok farklı alan için uygulanabilir kılmıştır. $\mathrm{Bu}$ uygulama alanları incelendiğinde, askeri alanda [25]; savaş pilotlarına yönelik askeri eğitim uygulaması [26] ile örneklenebilen bu teknoloji savaș pilotlarının kaskına yerleştirilen ve göz hizası seviyesinde kullanılan saydam özellikli ekranlarda kullanılmıştır. $\mathrm{Bu}$ ekranlar pilotların görmesi gereken uçuş verilerini anlık olarak göstermektedir. Donanımın saydam yapısı sayesinde pilotların gerçek görüntü ile veri ekran görüntüsünü aynı anda görmesi amaçlanmıştır. $\mathrm{Bu}$ alan ve çalışmalardan biri olan ĕgitim alanında; Billinghurst, Kato ve Poupyrev (2001) [16] tarafindan artırılmış gerçeklik öğrenme ortamı tasarlanmıştır. B. E. Shelton ve arkadaşları (2002) [27] dünya ve güneş sistemi arasındaki ilişkiyi AG teknolojisi ile açıklamışlardır. Liarokapis ve arkadaşları (2002) [28] AG tabanlı eöğrenme sistemi yapmışlardır. Müze alanında; D. Wagner ve arkadaşları (2005) [29] tarafından artırılmış gerçeklik üzerine elektronik bir tur rehberi geliştirilmişlerdir. A. Damala ve arkadaşları (2007) [30] sadece ziyaretçileri değil aynı zamanda müze çalışanlarının da kullanabilecekleri profesyonel ve birden fazla multimedia özelliğine sahip bir mobil cihaz gerçekleştirmişlerdir. Aynı zamanda săğlk alanında; Sielhorst ve arkadaşları (2004) [31] kalp atışı ve nabız gibi gerçek hasta verilerini gösterme işlemini AG ile yapmaya çalışmışlardır. Pisano, (1998) [32] artırılmış gerçeklik kullanarak göğüs kisti uygulaması tasarlamıştır. State, Chen ve arkadaşları (1994) [33] artırılmış gerçeklik temelli ultrasonografi işlemi üzerinde çalışmışlardır. Patel, Vannier ve arkadaşları (1996) [34]; Taylor, Funda ve arkadaşları (1996) [35] kraniyofasiyal cerrahi görselleștirme ve simülasyon sistemleri üzerine çalışmalar yapmışlardır. Diğer çalışma olan gezi alanında; Höllerer ve Feiner (2004) [36] AG tabanlı tarihi olay üzerine incelemeler yapmışlardır. Vlahakis ve arkadaşları (2001) [37] kültürel miras alanı mobil bilgi sistemi çalışmasında artırılmış gerçeklik teknolojisini kullanmışlardır. Vlahakis ve arkadaşları (2004) [38] tarafindan 2004 tarihinde "ArcheoGuide" isimli AG tabanlı bir uygulama yapılmıştır. Bu uygulama arkeolojik sit alanlarında kişiye özgü rehberlik sunmaktadır. İlk örnek çalışmasında Yunanistan'ın Olimpiya Antik Kenti seçilmiş ve buradaki Antik Stadyum' da yarışan sanal atletler için AG çalışmasını yapmışlardır. Bir diğer çalışma olan tasarım alanında; Collett ve MacDonald (2006) [39] AG ile robot programının geliştiriciye yönelik görselleştirilmesi işlemi yapmıștır. Örnekleri verilen bu artırılmış gerçeklik alanlarına "imalat" [40-41], "doğal afet" [42], "sanat" [43], "reklam" [44], "eğlence" [45], "mühendislik" [46] ve "güvenlik" [47] gibi alanları da ekleyebiliriz.

\subsection{Artırılmış Gerçeklik için Kullanılan Çevre Birimleri (Peripherals used for Augmented Reality)}

\subsubsection{Donanım (Hardware)}

Donanım alt yapıs1, kullanıcinın AG teknolojisini tam olarak kullanabilmesi ve yazılımın uygulama aşamasında kendisine verilen görevi yapabilmesi için önemlidir. Artırılmış gerçekliğin dış ortamdan gelen veri ve görüntüleri alıp gerçek dünya ile birleştirme işlemi olduğu dikkate alınırsa her $A G$ ortamı için bu verilere ulaşabilmenin yolu bazı donanımların kullanılmasını gerektirmektedir [1]. Alan B. Craig [48], Artırılmış Gerçekliği Anlamak: Kavramlar ve Uygulamalar adlı kitabında AG sistemlerinin donanımsal anlamda gerçekleştirilmesi için algılayıcılar, işlemciler ve görüntüleyiciler olarak üç temel bileşene gerek olduğunu vurgulamaktadır [49]. AG ortamları için ihtiyaç duyulan bileşenler (i) algılayıcılar için GPS ve kamera, (ii) görüntüleyiciler için tablet veya taşınabilir ekran, (iii) işlemciler için masaüstü veya mobil PC olabilir.

\subsubsection{Yazllım (Software)}

Artırılmış gerçeklik için öncelikle sanal ile gerçek ortamı bir arada yorumlayacak bir ara yüzey gerekmektedir ve çoğunlukla bu ara yüzey yazılım firmaları tarafından kendi tescilledikleri yazılım paketleri olarak piyasaya sürülmektedir [1]. Bu yazılımlar, bazı araçlarla beraber tasarlanmaktadır. Yazılımlar genelde modelleme aracı, işaretçi (ing: marker) üretim aracı, performans artırıcı motor arac1 ve mobil uygulama arac1 (HTML5, Cross Platform, Native, Hybrid vb.) isimleri altında gelmektedir [50].

AG teknolojisini içeren birçok kütüphane yazılım aracında mevcuttur. Bunlar açık kaynak kodlu ve ticari olmak üzere ikiye ayrılır. ARToolKit [51], açık kaynak kod yazılımda bilinen ve en çok kullanılan yazılım paketi kütüphanesidir. ARToolKit, 1999 yılında Hirokazu Kato tarafindan geliştirilmiş, Washington üniversitesi HIT Laboratuvarı (The Human Interface Technology Laboratory) tarafından yayınlanmış, C dilinde yazılmış, farklı dillerde desteği olan ücretsiz bir kütüphanedir. Bu kit kamera ve marker olarak ifade edilen fiziksel bir işaretçinin konumunu gerçek zamanlı hesaplayıp istenen görüntüyü işaretçi üzerinde görüntüleme becerisine sahip bir kütüphane olarak tanımlanabilir [1]. 
ARToolKit kütüphanesinden türetilmiş farklı dilleri destekleyen yazılım sürümleri Şekil 2'de gösterilmektedir.

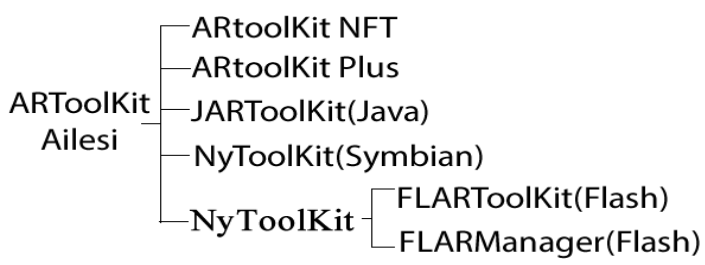

Şekil 2. ARToolKit Ailesi (ARToolKit Family)

Tablo 1, açık kaynak kodlu AG platformların yansitmaktadır.

Tablo 1. Açık kaynak kodlu AG platformları (Open source AR platforms)

\begin{tabular}{|c|c|c|c|c|}
\hline Donanım & $\begin{array}{l}\text { İşletim } \\
\text { Sistemi }\end{array}$ & $\begin{array}{l}\text { Çalışma } \\
\text { Ortamı }\end{array}$ & $\begin{array}{c}\text { ARToolkit } \\
\text { Ailesi }\end{array}$ & 3D Motor \\
\hline \multirow{4}{*}{ Masaüstü } & \multirow{4}{*}{$\begin{array}{l}\text { Windows } \\
\text { Mac OS }\end{array}$} & \multirow{2}{*}{ Flash } & \multirow{2}{*}{ FLARToolKit } & Away 3D \\
\hline & & & & Papervision 3D \\
\hline & & \multirow{2}{*}{ Silverlight } & \multirow{2}{*}{ SLARToolKit } & Silverlight $53 \mathrm{D}$ \\
\hline & & & & Balder \\
\hline \multirow{3}{*}{ Mobil } & IOS & $\begin{array}{c}\text { Native } \\
\text { (Objective } \\
\text { C) }\end{array}$ & $\begin{array}{c}\text { IOS için } \\
\text { ARToolKit }\end{array}$ & $\begin{array}{l}\text { OpenSceneGraph } \\
\text { (OpenGL) }\end{array}$ \\
\hline & Android & $\begin{array}{l}\text { Native } \\
\text { (Java) }\end{array}$ & $\begin{array}{l}\text { ARToolKit/ } \\
\text { AndAR }\end{array}$ & OpenGL \\
\hline & $\begin{array}{l}\text { Windows } \\
\text { Phone }\end{array}$ & $\begin{array}{l}\text { Native(C\#)/ } \\
\text { Mango/ } \\
\text { Silverlight }\end{array}$ & SLARToolKit & Native(C\#) \\
\hline
\end{tabular}

AG ortam uygulamaları oluşturabilmek için ARToolKit dışında Augment, Vuforia, Aurasma, Wikitude, Layar gibi yazılım geliştirme araçları/platformları/frameworks (SDK, Software Development Kit) mevcuttur. Bu yazılım araçlarından bazıları serbest dağıtılırken bazıları ticari olarak satılmaktadır. Bu SDK'lar hakkında ayrıntılı bilgi Tablo 2'de verilmektedir.

Tablo 2. AG uygulama geliştirme platformları (AR application development platforms)

\begin{tabular}{|c|c|c|c|c|c|}
\hline AR Frameworks & Vuforia & ARToolKit & WikiTude & Layar & Kudan \\
\hline Şirket & PTC & DAQRI & $\begin{array}{c}\text { Wikitude } \\
\text { GmbH }\end{array}$ & $\begin{array}{c}\text { BlippAR } \\
\text { Group }\end{array}$ & $\begin{array}{l}\text { Kudan } \\
\text { Limited }\end{array}$ \\
\hline Lisans & \begin{tabular}{|c|} 
Serbest \\
ve Ticari \\
\end{tabular} & Serbest & Ticari & Ticari & Ticari \\
\hline $\begin{array}{l}\text { Desteklenen } \\
\text { Platformlar }\end{array}$ & $\begin{array}{c}\text { Android, } \\
\text { IOS,Unity }\end{array}$ & $\begin{array}{c}\text { Android, } \\
\text { IOS, } \\
\text { Windows, } \\
\text { Linux, Mac } \\
\text { OS X, SGI }\end{array}$ & $\begin{array}{l}\text { Android, IOS, } \\
\text { Google Glass, } \\
\text { Epson Moverio, } \\
\text { Vuzix M-100, } \\
\text { Optinvent } \\
\text { ORA1, } \\
\text { PhoneGap, } \\
\text { Titanium, } \\
\text { Xamarin }\end{array}$ & $\begin{array}{c}\text { IOS, } \\
\text { Android, } \\
\text { BlackBerry }\end{array}$ & $\begin{array}{c}\text { Android, } \\
\text { IOS, } \\
\text { Unity }\end{array}$ \\
\hline
\end{tabular}

Modelleme aracı, AG teknolojisinin en önemli bileşenlerinden birisidir. $\mathrm{Bu}$ araçlar $\mathrm{XYZ}$ koordinat sistemine göre çalışır. Modelleme aracında üç boyutlu modelleme ve karakter tasarlama imkânı sağlayan araçlar mevcuttur ve bu araçlar gerçek hayattaki bir nesnenin bilgisayarda üç boyutlu modellenmesini sağlar. 3D model ve grafik tasarlama programlarına Cinema 4D, Google SketchUp, K-3D, Sweet Home 3D, Maya ve 3DS Max, Blender, Unity3D örnek olarak verilebilir.

Performans artırıcı motor aracı, program içinde modelleme aracıyla yapılmış üç boyutlu nesnelerin(3D API) çalışmasına imkân sağlar. Birçok motor yazılım türü mevcuttur. Papervision3D, Away3D ve Sandy3D, WebGL ve Unity3D en çok bilinen ve yaygın kullanılan 3D motorlarıdır [1]

\subsection{3. İ̧̧aretçi (Marker)}

İşaretçiler sanal ile gerçek ortamı birleştirmek, aralarında etkileşimi sağlamak için kullanılan önemli bir AG aracıdır. Şekil 3'görüleceği gibi işaretçiler kamera tarafından daha iyi algılanmaları için beyaz kenarlıklı ile çevrelenmiş siyah zemin içine beyaz ve siyah desenler ile resmedilmektedir. İşaretçi üretim programları işaretçi desenindeki her bir pikselin renk tonunu ifade eden sayısal bir değer (0-255 arasında renk kodları) ile pat dosyalarında saklanmaktadır. Günümüzdeki gelişmeler gerçek dünyadaki bir nesnenin (gerçek bir bina, insan yüzü, duvardaki resim) işaretçi olarak kullanılmasına imkân vermektedir.

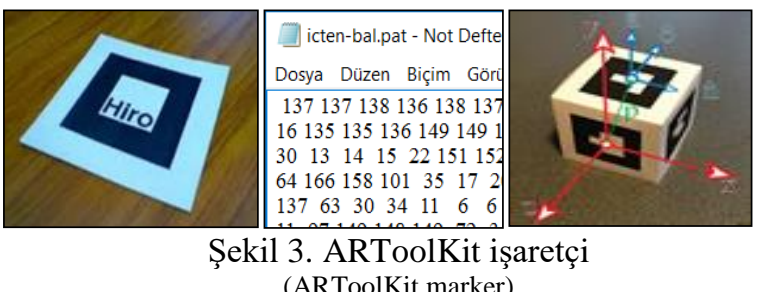

ARToolKit tipi işaretçiler $16 \times 16$ veya $32 \times 32$ boyutunda olabilir. $\mathrm{Bu}$ tip işaretçiler kare biçiminde olmalı ve kamera tarafindan alınan görüntünün yüzde 50'sinin sistemde kayıtlı olan "pat" uzantılı dosyalardaki sayısal değerlerle eşleşmesi gerekmektedir. Orta kalite düzeyindeki bir kamera ARToolKit tipi işaretçilerden saniyede 25 kare görüntü almakta, alınan görüntüye göre gerekli nesne 40 milisaniyede işaretçiye yüklenmektedir. $\mathrm{Bu}$ bağlamda işaretçi boyutundaki değişim verilen işlem sürelerinin de değişmesine sebep olacaktır. Şekil 4'de işaretçi ve kamera koordinatları arasındaki ilişki, Şekil 5'de ise işaretçi tanıma algoritması gösterilmiştir.

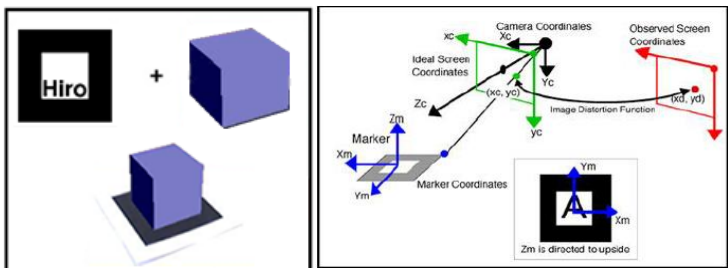

Şekil 4. İşaretçi ve kamera koordinatları arasındaki ilişki (Relation between marker and camera coordinates) 


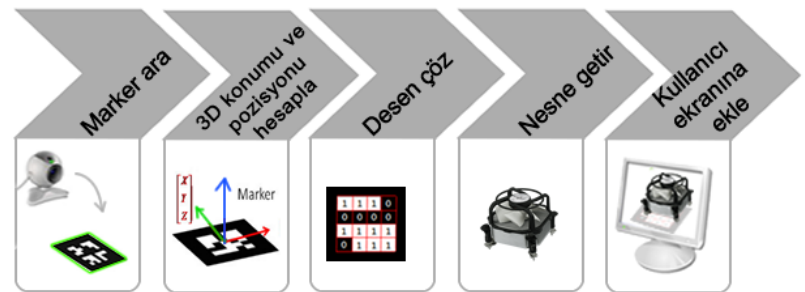

Şekil 5. İşaretçi işleme algoritmas1 (Marker processing algorithm)

\section{AMAÇ VE ARAŞTIRMA SORULARI (PURPOSE AND RESEARCH QUESTIONS)}

Artırılmış gerçeklik alanında yapılan çalışmaları inceleyen araştırmacılar az da olsa mevcuttur. Bunlardan Türkiye adresli araştırmalardan birkaç örnek şu şekildedir; Korucu ve arkadaşları (2016) [52] 2007-2016 tarihleri arasında ülkemizde eğitim alanı için oluşturulmuş artırılmış gerçeklik teknolojisini konu alan 33 akademik çalışmayı 8 kategoride içerik analiz yöntemi ile incelemişlerdir. Arslan ve Elibol (2015) [53] mobil cihazlar için geliştirilmiş Google Play'de ilk listelenen 100 adet eğitsel artırılmış gerçeklik uygulamasını çeşitli açıdan incelemişlerdir. Yılmaz ve Batdı (2016) [54] metaanaliz boyutu kapsamında, artırılmış gerçeklik uygulamalarının akademik başarı üzerindeki etki büyüklüğünü belirlenmesi amaciyla ulusal ve uluslararasındaki alandaki 12 çalışmanın verilerini analiz etmişlerdir.

İlgili alanyazın incelendiğinde, AG teknolojisini içeren örnek çalışmaların genel olarak eğitim kazanımları üzerine odaklanıldığı anlaşılmaktadır. Buna karşın daha geniş AG uygulama alanının seçilmesi, bu teknoloji ile yapılmış uygulamalarının sahip oldukları ortak ya da farklı özellikler açısından incelenmesi ve sonuçlarının değerlendirilmesi gelecek çalışmalar için daha kullanışlı, nitelikli ve kapsamlı sonuçların elde edilmesini sağlayacağı düşünülmektedir. Bütün bunlar dikkate alındığında bu çalışma; 2010-2016 yılları arasında ulusal ve uluslararası dergilerde yayınlanmış AG teknolojisi alanındaki akademik çalışmaları örnekleme yöntemine göre incelemeyi amaçlamaktadır. Çalışma kapsamında aşağıdaki araştırma sorularına cevap aranmıştır:

1. Çalışmaların yayım yılına göre dağglımı nasıldır?

2. Çalışmaların yayınlandıkları dergilere göre dağılımı nasildır?

3. Çalıșmaların AG türü dağılımı nasıldır?

4. Çalışmaların görüntüleme sistemleri dağılımı nasıldır?

5. Çalışmaların uzamsal görüntüleme sistemleri dağılımı nasildir?

6. Çalışmaların taşınabilir görüntüleme sistemleri dağılımı nasıldır?

7. Çalışmaların AG özelliğinin üzerinde çalıştığı başa monte edilen görüntüleme sistemleri cihaz ve yıl dağılımı nasıldır?

8. Çalışmalarda çalışma ile kullanıcı arasında kullanılan etkileşim yöntemleri ve yıl dağılımı nasıldır?
9. Çalışmalarda kullanılan AG Araçları

(AR Frameworks) dağılımı nasıldır?

\section{YÖNTEM (METHOD)}

$\mathrm{Bu}$ çalışmada, artırılmış gerçeklik teknolojisine sahip ulusal ve uluslararası akademik çalıșmaların sahip olduğu özellikleri incelemek için nitel araştırma türlerinden içerik analizi modeli kullanılmıştır. İçerik analizi, okuyucuların anlayacağı bir dilde hazırlanan [55], birbirine benzeyen verileri belirli kavramlar ve temalar çerçevesinde bir araya getirmek [56], yinelenebilir [57], sözel, yazılı ve diğer materyallerin nesnel ve sistematik bir şekilde incelenmesine olanak tanıyan bilimsel bir yaklaşımdır [58]. Araştırma süreci ve kullanılan yöntemler ayrıntılı bir şekilde aşağıda açıklanmaktadır.

\section{1. Örneklem (Sampling)}

Araştırmanın evrenini, artırılmış gerçeklik teknolojisine sahip çalışmalar oluşturmaktadır. Çalışmada örnekleme yöntemi olarak "amaçlı örnekleme" yöntemi kullanılmıştır. Araştırmacı örneklem için hangi birimlerin seçileceğine kendisi karar verir. Araştırmacının uygun gördüğü kümeler, gruplar, birimler araştırmanın amacına da uygun olarak belirlenir. $\mathrm{Bu}$ nedenle, bu tip örneklemeye yargısal örnekleme de denilir [59]. Araştırmanın örneklemini ise, 2010-2016 yılları arasında yayınlanan ve içinde artırılmış gerçeklik teknolojisi kavramı geçen 34 akademik çalışma oluşturmaktadır. Örneklem işlemi 3 aşamada gerçekleştirilmiştir. Birinci aşamada artırılmış gerçeklik ile ilgili yapılan çalışmalara ulaşabilmek için zaman filtresi (2010-2016) ile beraber "artırılmış gerçeklik, augmented reality" anahtar kelimelerini kullanarak ULAKBİM, Google Scholar, Science Direct, Yükseköğretim Kurulu Ulusal Tez Merkezi yayın dizinleri ile DergiPark taranmıştır. İkinci aşamada tarama sonucunda erişilebilen çalışmaların erişim izinlerine, kapsamına, araştırmanın amacına ve alanına ulaşabilme ölçütlerine göre taranarak 105 çalışma belirlenmiştir. Üçüncü aşamada belirlenen çalışmalarda artırılmış gerçeklik teknolojisine odaklanmayan çalışmalar çıkartılmış ve bu sayı 34 akademik çalışmaya düşürülmüştür.

\subsection{Veri Toplama Aracı (Data Collection Instrument)}

$\mathrm{Bu}$ çalışmada veri toplama aracı olarak araştırmacılar tarafindan geliştirilen ölçek kullanılmıştır. Çalışmada yer alan yararlı verilerin elde edilmesi, düzenlenmesi ve tekrarlı verilerden arındırılması için taslak ölçek oluşturulmuş, devamında araştırmacıların görüşleri ve alan uzmanı tavsiyesi doğrultusunda bu ölçek içinde yer alacak alanlara ekleme ve çıkartmalar yapılarak son hali verilmiştir. Araştırmacılar tarafından veri toplama aracı olarak kullanılacak ölçek ile çalışmaya dâhil edilen araştırmaların bilgileri toplanmıştır. $\mathrm{Bu}$ bilgiler araştırmanın; yayım yılı, yayım yeri(makale/kitap/tez), AG türü(işaretçi kullanım tipi), görüntüleme sistem türü(uzamsal/optik/taşınabilir), kullanıcı ve cihaz 
etkileşim şekli ve kullanılan AG aracı(fireworks) ile ilgili bilgilerdir.

\subsection{Verilerin Analizi (Analysis of the Data)}

İçerik analiz yöntemi kullanılarak incelenen çalışmalardan elde edilen veriler betimsel istatistikî yöntemler (yüzde ve frekans) kullanılarak çözümlenmiştir. Örneklemi oluşturan 34 çalışmanın ölçek verileri, bilgisayar ortamında Microsoft Excel programına yüklenmiştir. Yükleme esnasında oluşabilecek yanlıs veri girişlerini önlemek amacıyla veri kontrol denetimleri yapılmıştır. Veriler Excel programına yüklendikten sonra araştırma soruları 1şı̆̆ında istatistiki hesaplamalar yapılmış, çıkan sayısal veri sonuçlarının daha anlaşılır bir şekilde ifade edilebilmesi için çizelgeler ve grafikler kullanılmıştır. Elde edilen sonuçlar tartışma, sonuç ve öneriler bölümünde yorumlanmıştır.

\subsection{Geçerlik ve Güvenirlik (Validity and Reliability)}

Araştırmacılar seçilen çalışmaların güvenilirliğini ve geçerliliğini sağlamak amacıyla araştırma kapsamında bulunan çalışmaları paylaşmışlardır. Sınıflandırma sürecinin ilk aşamasında her araştırmacı bağımsız bir şekilde kendi araştırma çalışmasını incelemiştir. İkinci aşamada araştırma makaleleri araştırmacılar tarafindan değiştirilerek ikinci bir incelemeye tabi tutulmuştur. Üçüncü aşamada araştırmacılar tarafindan elde edilen verilerin doğruluğu karşılaştırılarak yorum farkından kaynaklı veriler belirlenmiştir. Kontrol sırasındaki yorum farklılıkları araştırmacılar tarafından tartışılmış ve bazı durumlarda bu alanda çalışması olan uzman görüşü alınarak giderilmeye çalışılmıştır. Son aşamada araştırmacılardan biri elde edilen verileri veri tabanına girmiş, diğer araştırmacı girilen verilerin doğruluğunu tekrar inceleyerek veri giriş doğrulamasını sağlamıştır. Bu şekilde iç, dış geçerliliği ve güvenilirliği sağlanmaya çalışılmıştır.

\section{BULGULAR (FINDINGS)}

İçerik analiz yöntemi kullanılarak incelenen çalışmalardan elde edilen veriler 9 adet araştırma sorusu temel alınarak analiz edilmiştir. Bu bölümde, analizler sonucunda elde edilen bulgular yüzde ve frekans dağılımları dikkate alınarak aşağıda sunulmuştur.

\subsection{AG Çalışmaların Yayım Yılına Göre Dağılımı (The distribution of AR studies by publication year)}

Çalışma kapsamında incelenen 34 çalışmanın yayım yılına göre dağılımı Tablo 3'de gösterilmektedir.
Tablo 3. AG çalışmaların yayım yılına göre dağılımı ( The distribution of AR studies by publication year)

\begin{tabular}{|c|c|c|}
\hline \multirow{2}{*}{ Yayın Yılı } & Çalışma Sayısı (N) & Yüzde (\%) \\
\hline 2010 & 3 & 8,8 \\
\hline 2011 & 2 & 5,9 \\
\hline 2012 & 7 & 20,6 \\
\hline 2013 & 7 & 20,6 \\
\hline 2014 & 5 & 14,7 \\
\hline 2015 & 4 & 11,8 \\
\hline 2016 & 6 & 17,6 \\
\hline Toplam & 34 & 100 \\
\hline
\end{tabular}

$\mathrm{N}=$ Çalışma sayısı

Tablo 3 incelendiğinde, 2010-2014 yıllar arasında her yıla en az 2 çalışmanın yapıldığı, en çok çalışmanın \% 20,6 ile 2012 ve 2013, en az çalışmanın \% 5,9 ile 2011 yılında yapıldı̆̆ı görülmektedir. Yapılan çalışmaların \% 55,9'su 2012-2014 yılları arasında yapılmış olduğu Tablo 3'de gözlemlenmektedir.

\subsection{AG Konulu Çalışmaların Dergilere Göre Dağılımı} (The distribution of AR studies by publication magazine)

Araştırmaya dâhil edilen çalışmalar yayınlandıkları dergi veya kitaplara göre analiz edilerek Tablo 4'deki veriler elde edilmiştir.

Tablo 4. AG çalışmaların yayınlandıkları dergilere göre dağılımı

(The distribution of AR studies by publication journals )

\begin{tabular}{|l|c|c|l|c|c|}
\hline \multicolumn{1}{|c|}{$\begin{array}{c}\text { Yayınlandığı } \\
\text { Dergi/Kitap }\end{array}$} & $\mathrm{N}$ & $\%$ & & $\mathrm{~N}$ & $\%$ \\
\hline AKÜ FEMÜBİ & 1 & 2.9 & ijca & 1 & 2.9 \\
\hline Harran Univ. JOofEng. & 1 & 2.9 & IJCSCL & 1 & 2.9 \\
\hline Akademik Bilişim & 1 & 2.9 & ijimai & 1 & 2.9 \\
\hline ASEE & 1 & 2.9 & IRJET & 1 & 2.9 \\
\hline BJET & 1 & 2.9 & JITE & 1 & 2.9 \\
\hline CACIC & 1 & 2.9 & JITTE & 1 & 2.9 \\
\hline Computers \& Education & 2 & 5.9 & Jret & 1 & 2.9 \\
\hline DAAAM & 1 & 2.9 & Mlearn2016 & 1 & 2.9 \\
\hline ICCCBE & 1 & 2.9 & Pajes & 1 & 2.9 \\
\hline icdvrat & 1 & 2.9 & Procedia & 2 & 5.9 \\
\hline IEEE & 6 & 17.6 & $\begin{array}{l}\text { Scholarship } \\
\text { at Uwindsor }\end{array}$ & 1 & 2.9 \\
\hline IJAIED & 1 & 2.9 & Toplam & 34 & 100 \\
\hline IJARCCE & 1 & Sensors & 1 & 2.9 \\
\hline ijarcce & 2.9 & Tojet & 1 & 2.9 \\
\hline N=Çalışa sayısı & 1 & & & \\
\hline
\end{tabular}

$\mathrm{N}=$ Çalışma sayısı 
Araştırmada 34 çalışmanın 27 farklı dergi veya kitapta yayınlanmış olduğu görülmektedir. Tablo 4 detaylı olarak incelendiğinde AG konulu çalışmaların 2010-2016 yılları arasında en çok $(\mathrm{N}=6, \%=17,6)$ IEEE dergisinde yayınlandığı görülmektedir. Bunun ardından 2'şer çalışma ile Computer\&Education ve Procedia dergisi takip etmektedir. Diğer 24 dergi veya kitapta 1 'er kez çalışma yayınlandığı anlaşılmaktadır.

\subsection{AG Türü Dă̆llımı (The distribution of AR type)}

Alanyazın incelendiğinde Cheng ve Tsai (2013) [60], Sirakaya ve Seferoğlu (2016) [15] ve ibili (2013) [61] tarafindan yapılmış olan çalışmalarda AG sistemleri resim tabanlı (image-based) ve konum tabanlı (location-based) olmak üzere iki kategoride toplanmaktadır. $\mathrm{Bu}$ çalışmalarda resim tabanlı AG sistemleri de 3 boyutlu modelin görüleceği yere göre işaretçi tabanlı sistemler (İTAG) ve işaretçi tabanlı olmayan sistemler (İTOAG) olarak sınıflandırılmaktadır. Ayrıca Esengün (2016) [62] yüksek lisans tezinde $A G$ uygulamalarının çoğunlukla "geo-location based AR" ve "marker-based AR" şeklinde olduğunu ifade etmiştir. Cherchi ve ark. (2014) [63] tarafindan yapılan çalışmada ise AG türü "geo-localized AR" ve "ARTags" şeklinde ifade edilmektedir. Artırılmış gerçeklik uygulamaları geliştirilirken 3 farklı AG uygulama işleminden söz edilebilir [64]. Uluyol (2016) [6] çalışmasında bunları; (1) işaretleyici tabanlı, (2) işaretleyicisiz tabanlı ve (3) konum tabanlı olarak belirtmektedir. Diğer taraftan bazı çalışmalarda AG türü; (1) işaretçi tabanlı (marker based), (2) işaretleyiçisiz tabanlı (markerless based), (2.1) görü-tabanlı (vision based), (2.2) konum tabanlı (location based) olarak da sinıflandırılmaktadır.

$\mathrm{Bu}$ çalışmada AG türü resim(görsel) tabanlı ve konum tabanlı AG olarak alınmıştır. Konum tabanlı ve resim tabanlı sistemler açıklanmak istenirse; konum tabanlı AG, küresel konumlama (GPS), Kablosuz Yerel Alan Ağ (WLAN) veya Wi-Fi konumlama sistemleri tarafindan belirlenen mobil cihazların konum verilerini kullanmaktadır. Resim (görüntü) tabanlı AG (ses, resim, el hareketi, 3D model) ise ortamdaki nesneleri işaret referansı olarak kullanmaktadır. Bu nesne ortamdaki resim (ITAG yapısına) veya ses/el hareketi (ITOAG yapısına) olabilir.

Tablo 5 artırılmış gerçeklik çalışmalarında kullanılan izleme yöntemlerin sayılarının yıllara göre dağılımını, Şekil 6 ise bu dağılımın grafiğini yansıtmaktadır.
Tablo 5. AG türü kullanımının yıllara göre dağılımı

\begin{tabular}{|c|c|c|c|}
\hline \multirow{2}{*}{ Y11 } & \multicolumn{2}{|c|}{ Resim Tabanlı AG } & \multirow{2}{*}{$\begin{array}{c}\text { Konum } \\
\text { Tabanlı }\end{array}$} \\
\cline { 2 - 4 } & $\begin{array}{c}\text { İşaretçi } \\
\text { Tabanlı }\end{array}$ & $\begin{array}{c}\text { İşaretçi Tabanlı } \\
\text { Olmayan }\end{array}$ & \\
\hline \multirow{2}{*}{ (İTAG) } & (ITOAG) & (KTAG) \\
\hline 2010 & 3 & 0 & 0 \\
\hline 2011 & 2 & 0 & 0 \\
\hline 2012 & 6 & 1 & 0 \\
\hline 2013 & 6 & 0 & 1 \\
\hline 2014 & 3 & 2 & 0 \\
\hline 2015 & 4 & 0 & 0 \\
\hline 2016 & 4 & 1 & 1 \\
\hline Toplam & 28 & 4 & 2 \\
\hline
\end{tabular}

İTAG: İşaretçi tabanlı artırılmış gerçeklik (Marker based),

ITOAG: İşaretçi tabanlı olmayan artırılmış gerçeklik (Marker-less based) KTAG: Konum tabanlı artırılmış gerçeklik (Location based)

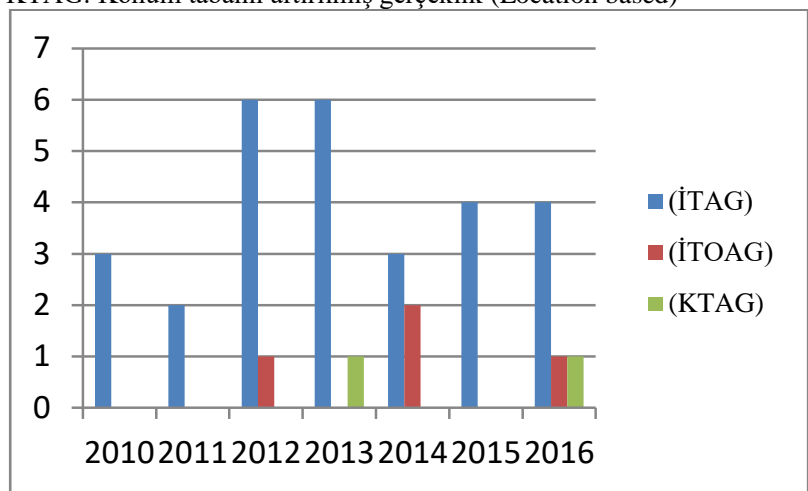

Şekil 6. AG türü kullanımının yıllara göre dağılımı (The distribution of AR type usage by years)

Şekil 6'ya bakıldığında, İTAG türünde en çok çalışmanın yapıldığ1 $2012(\mathrm{~N}=6)$ ve $2013(\mathrm{~N}=6)$ y1lları olduğu, en az çalışmanın $2011 \quad(\mathrm{~N}=2)$ yılı olduğu görülmektedir. ITOAG türünden bakıldığında; 2014 yılı iki yayın ile en çok yayın yılı olduğu, 2012 ve 2016 yılları 2'şer çalışmanın olduğu, diğer yıllarda yapılan bir çalışmanın bulunmadığ1 görülmektedir. 2013 ve 2016 tarihlerinde KTAG türünden sadece 1 'er yayın yapıldı̆̆ 1 anlaşılmaktadır. Şekil 6'dan 2010-2016 yılları arasındaki her yıl en az 2'şer İTAG çalışmasının olduğu, buna karşın İTOG ve KTAG çalışmalarının 2010, 2011 ve 2015 yıllarında bulunmadığı anlaşılmaktadır. Şekil 6 genel olarak değerlendirildiğinde, çalışmalarda çoğunlukla İTAG $(\mathrm{N}=28)$ türünün kullanıldı $\breve{g}_{1}$ ve bunu sirasıyla İTOAG $(\mathrm{N}=4)$ ve KTAG $(\mathrm{N}=2)$ türlerinin takip ettiği görülmektedir.

\subsection{AG Çalışmaların Üzerinde Çalıștığl Cihaz Teknolojisi Dağllımı (The distribution of AR imaging systems)}

AG sistem yapısının oluşturulmasındaki temel işlem sanal ile gerçeğin nasıl birleştirileceğidir [65]. Funchs \& Ackerman (1999)[65] ve Azuma (1997) [5] tarafindan 
yapılan çalışmalarda görüntüleme sistemleri optik tabanlı sistemler, video tabanlı sistemler ve monitör tabanlı sistemler olarak siniflandırılmaktadır. $\mathrm{Bu}$ inceleme çalıșmasında günümüzdeki masaüstü veya taşınabilir bilgisayarların (cihaz) fiziksel boyutlarındaki küçülme, dâhili ve harici görüntüleme sistemlerindeki gelişme, artırılmış gerçeklik gözlüğü (VRBox) içinde mini bilgisayarların göz hizasında kullanılması gibi durumlardan dolayı monitör tabanlı sistemler video tabanlı sistemler altında toplanmıştır.

Tablo 6'da uzamsal görüntü sistemlerinin ve taşınabilir görüntü sistemlerinin oluşturduğu video tabanlı sistemler ve başa monte edilen görüntüleme sistemi olan optik tabanlı sistemler olmak üzere iki kategoriye ayrılmış görüntüleme sistemlerinin tablo hali görülmektedir.

Tablo 6. AG görüntüleme sistemleri (AR imaging systems)

\begin{tabular}{|c|c|c|c|c|c|c|c|c|c|c|}
\hline \multirow{2}{*}{\multicolumn{2}{|c|}{$\begin{array}{l}\text { Üzerinde Çalıştığı } \\
\text { Cihaz } \\
\text { (Görüntüleme } \\
\text { Sistemleri) }\end{array}$}} & \multicolumn{7}{|c|}{ Yillar } & \multicolumn{2}{|c|}{ Toplam } \\
\hline & & 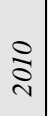 & $\underset{i}{\bar{d}}$ & $\frac{\pi}{\grave{2}}$ & $\underset{\sim}{\stackrel{n}{2}}$ & $\stackrel{ \pm}{\stackrel{2}{2}}$ & $\stackrel{n}{\stackrel{2}{s}}$ & $\stackrel{\bullet}{\stackrel{2}{\Xi}}$ & $N$ & $\%$ \\
\hline \multirow{2}{*}{$\begin{array}{c}\text { Video } \\
\text { Tabanlı } \\
\text { Sistemler }\end{array}$} & $\begin{array}{l}\text { Uzamsal } \\
\text { Görüntüleme } \\
\text { Sistemleri }\end{array}$ & 3 & 2 & 6 & 5 & 2 & 3 & 2 & 23 & 67.6 \\
\hline & $\begin{array}{l}\text { Taşınabilir } \\
\text { Görüntüleme } \\
\text { Sistemleri }\end{array}$ & - & - & 1 & 2 & 2 & 1 & 3 & 9 & 26.5 \\
\hline $\begin{array}{c}\text { Optik } \\
\text { Tabanlı } \\
\text { Sistemler }\end{array}$ & $\begin{array}{l}\text { Başa Monte } \\
\text { Edilen } \\
\text { Görüntüleme } \\
\text { Sistemleri }\end{array}$ & - & - & - & - & 1 & - & 1 & 2 & 5.9 \\
\hline \multicolumn{2}{|c|}{ Toplam } & 3 & 2 & 6 & 5 & 2 & 3 & 2 & 34 & 100 \\
\hline
\end{tabular}

Tablo 6, incelenen çalışmalarda kullanılan AG görüntüleme sistemi kategorilerinin y1llara göre değişimini yansıtmaktadır. Tablo göz önünde bulundurulduğunda en çok çalışmanın $(\mathrm{N}=23, \% 67,6)$ uzamsal görüntüleme sistemleri üzerine yapıldı̆̆ görülmektedir. İkinci sırada $(\mathrm{N}=9, \% 36,5)$ taşınabilir görüntüleme sistemleri yer almaktadır. Bunu üçüncü ve son sırada olan, en az kullanılan (N=2, \% 5,9) başa monte edilen görüntüleme sistemleri takip etmektedir.

\subsection{AG Çalışmaların Üzerinde Çalıştı̆̆ Uzamsal Görüntüleme Sistemleri Dă̆llımı (The distribution of Spatial imaging systems)}

Tablo 7, farklı cihazlar ile olușturulmuş uzamsal görüntüleme sistemlerinin yıllara göre değişimini yansıtmaktadır. Tabloya bakıldığında, uzamsal görüntüleme yapısının her birinde PC (kişisel bilgisayar) donanım cihazının yer aldığı görülmektedir. Tablo derinlemesine incelendiğinde uzamsal özellikli çalışmaların büyük bir kısmında PC ve WebCam $(\mathrm{N}=16$, \%69,6) ikilisinin kullanılmış olduğu anlaşılmaktadır. Uzamsal özellikli 23 bilimsel çalışmanın içinde sadece $P C$ ve WebCam ikilisinin kullanıldığı 16 yayının olduğu, diğer uzamsal özellikli yapıların 7 yayın ile temsil edildiği görülmektedir. $\mathrm{Bu}$ sayısal değerler $\mathrm{PC}$ ve WebCam yapısının araştırmacılar tarafından daha çok tercih edildiği sonucuna ortaya çıkartmaktadır. Tablodaki diğer veriler incelendiğinde kalan 7 uzamsal özellikli yapının farklı yıllarda 1'er yayınla temsil edildiği anlaşılmaktadır.

Tablo 7. Uzamsal görüntüleme sistemleri (Spatial imaging systems)

\begin{tabular}{|c|c|c|c|c|c|c|c|c|c|}
\hline & \multicolumn{7}{|c|}{ Yillar } & \multicolumn{2}{|c|}{ Toplam } \\
\hline $\begin{array}{c}\text { Uzamsal } \\
\text { Görüntüleme } \\
\text { Sistemleri }\end{array}$ & 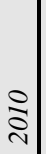 & $\bar{\curvearrowright}$ & 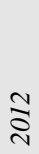 & $\stackrel{\Re}{\curvearrowright}$ & $\underset{\sim}{\stackrel{ \pm}{\sigma}}$ & $\frac{n}{\stackrel{\overbrace{}}{2}}$ & 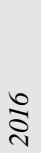 & $N$ & $\%$ \\
\hline PC+HMD+WebCam & 1 & - & - & - & - & - & - & 1 & 4.3 \\
\hline $\mathrm{PC}+\mathrm{WebCam}$ & 2 & 1 & 5 & 4 & 1 & 2 & 1 & 16 & 69.6 \\
\hline PC+HMD+Kamera & - & 1 & - & - & - & - & - & 1 & 4.3 \\
\hline PC+Proj.+Kamera & - & - & 1 & - & - & - & - & 1 & 4.3 \\
\hline PC+Proj.+WebCam & - & - & - & 1 & - & - & - & 1 & 4.3 \\
\hline PC+Proj+HMD+Kamera & - & - & - & - & 1 & - & - & 1 & 4.3 \\
\hline $\mathrm{PC}+\mathrm{HMD}$ & - & - & - & - & - & 1 & - & 1 & 4.3 \\
\hline PC+Kamera & - & - & - & - & - & - & 1 & 1 & 4.3 \\
\hline Toplam & 3 & 2 & 6 & 5 & 2 & 3 & 2 & 23 & 100 \\
\hline
\end{tabular}

Proj=Projeksiyon, HMD=Head-Mounted Display

\subsection{AG Çalıșmaların Üzerinde Çalıștığl Taşınabilir Görüntüleme Sistemleri Dă̆llımı (The distribution of Portable imaging systems)}

Tablo 8, taşınabilir görüntüleme sistemlerinden tablet ve telefon sayılarının yıllara göre dağılımını yansıtmaktadır. Grafik incelendiğinde tablet $(\mathrm{N}=7, \% 77,89)$ kullanımının telefon $(n=2, \% 22,2)$ kullanımına göre araştırmacılar tarafından daha fazla kullanıldığı görülmektedir. 
Tablo 8. Taşınabilir görüntüleme sistemleri (Portable imaging systems)

\begin{tabular}{|c|c|c|c|c|c|c|c|c|c|}
\hline \multirow{2}{*}{$\begin{array}{c}\text { Taşınabilir } \\
\text { Görüntüleme } \\
\text { Sistemleri }\end{array}$} & \multicolumn{7}{|c|}{ Yillar } & \multicolumn{2}{|c|}{ Toplam } \\
\hline & $\underset{\overbrace{}}{\stackrel{\overbrace{}}{\curvearrowright}}$ & $\underset{\precsim}{\curvearrowright}$ & 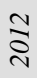 & $\underset{\sim}{\curvearrowright}$ & $\underset{\nabla}{\stackrel{\nabla}{\imath}}$ & $\stackrel{\curvearrowleft}{\curvearrowright}$ & 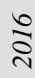 & $N$ & $\%$ \\
\hline $\begin{array}{l}\text { Taşınabilir } \\
\text { Cihaz } \\
\text { (Tablet) }\end{array}$ & - & - & 1 & 1 & 2 & 1 & 2 & 7 & 77.8 \\
\hline $\begin{array}{l}\text { Mobile } \\
\text { Cihaz } \\
\text { (Telefon) }\end{array}$ & - & - & - & 1 & - & - & 1 & 2 & 22.2 \\
\hline Toplam & 0 & 0 & 1 & 2 & 2 & 1 & 3 & 9 & 100 \\
\hline
\end{tabular}

5.7. AG Özelliğinin Üzerinde Çalıştı̆̆ Başa Monte Edilen Görüntüleme Sistemleri Dağılımı (The distribution of eadmounted imaging systems)

Tablo 9'da incelenen 34 çalışmanın sadece 2 çalışmasında optik tabanlı sistem(3D Glass) kullanıldı̆̆ görülmektedir.

Tablo 9. Başa monte edilen görüntüleme sistemleri (Head-mounted imaging systems by years)

\begin{tabular}{|c|c|c|c|c|c|c|c|c|c|}
\hline \multirow{2}{*}{$\begin{array}{l}\text { Başa monte } \\
\text { edilen } \\
\text { görüntüleme } \\
\text { sistemleri }\end{array}$} & \multicolumn{7}{|c|}{ Yillar } & \multicolumn{2}{|c|}{ Toplam } \\
\hline & 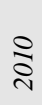 & $\underset{\sim}{\grave{D}}$ & $\underset{\sim}{\stackrel{D}{\delta}}$ & $\underset{\sim}{2}$ & $\frac{\nabla}{\sim}$ & $\underset{\sim}{\stackrel{n}{\sigma}}$ & 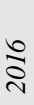 & $N$ & $\%$ \\
\hline 3D Glass & - & - & - & - & 1 & - & 1 & 2 & 100 \\
\hline Toplam & 0 & 0 & 0 & 0 & 1 & 0 & 1 & 2 & 100 \\
\hline
\end{tabular}

\subsection{AG Çalıșması ile Kullanıcı Arasında Etkileșim} Yöntemlerinin Yıllara Göre Dağılımı (AR Working-user interaction distribution by years)

Tablo 10, AG çalıșmalarının üzerinde çalıștığı cihaz ile kullanıcı arası etkileşim yöntemlerinin yıllara göre dağılımını yansıtmaktadır. Tablo incelendiğinde, Dokunma $(\mathrm{N}=10, \% 25)$ ve Fare/Klavye $(\mathrm{N}=10, \% 25)$ etkileşiminin AG çalışmalarında en fazla kullanıldığ 1 anlaşılmaktadır. Bunu Ek bir İşaretleyici $(\mathrm{N}=7, \% 17,5)$, Belirtilmemiş ( $\mathrm{N}=6, \% 15)$, Ek donanım ( $\mathrm{N}=4, \% 10)$, Hareket algılama $(\mathrm{N}=2, \% 5)$ yöntemlerinin takip ettiğ görülmektedir. Ez az kullanılan yöntemin ise fiziksel bir buton ile sağlanan etkileşim olduğu anlaşılmaktadır.
Tablo 10. AG Çalışma-Kullanıcı etkileşim dağılımı (AR Working-user interaction distribution by years)

\begin{tabular}{|c|c|c|c|c|c|c|c|c|c|}
\hline \multirow{2}{*}{$\begin{array}{c}\text { Uygulamanın } \\
\text { Üzerinde Çalıştığı } \\
\text { Cihaz ile Kullanıcı } \\
\text { Arası Etkileşim } \\
\text { Yöntemi }\end{array}$} & \multicolumn{7}{|c|}{ Yillar } & \multicolumn{2}{|c|}{ Toplam } \\
\hline & 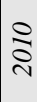 & $\underset{\sim}{\stackrel{\sim}{~}}$ & $\underset{\sim}{\stackrel{1}{2}}$ & $\frac{m}{i}$ & $\frac{\nabla}{\sim}$ & $\stackrel{n}{\delta}$ & 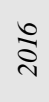 & $N$ & $\%$ \\
\hline Dokunma & - & - & 1 & 2 & 3 & 1 & 3 & 10 & 25 \\
\hline Ek Bir işaretçi & 1 & - & 1 & 2 & - & 3 & - & 7 & 17.5 \\
\hline Fare/ Klavye & - & 1 & 3 & 4 & - & 1 & 1 & 10 & 25 \\
\hline Buton (3D Gözlük) & - & - & - & - & 1 & - & - & 1 & 2.5 \\
\hline Ek Donanım & - & - & $3 *$ & - & - & - & $1 * *$ & 4 & 10 \\
\hline $\begin{array}{l}\text { Hareket Algilama } \\
\text { (Gesture-Open CV) }\end{array}$ & - & - & - & - & 2 & - & - & 2 & 5 \\
\hline $\begin{array}{l}\text { Kullanılmamış } \\
\text { (Belirtilmemiş) }\end{array}$ & 2 & 1 & 1 & - & - & - & 2 & 6 & 15 \\
\hline
\end{tabular}

* Arduino / Eldiven / Ses Alıcı, ** Sensör

\subsection{AG Çalışmasında Kullanılan AG Araç Dağılımı (The} distribution of AR Frameworks)

Tablo 11. AG Araçları dağılımı (The distribution of AR Tools)

\begin{tabular}{|l|c|c|}
\hline \multirow{2}{*}{ AG Araçları } & \multicolumn{2}{c|}{ Toplam } \\
\cline { 2 - 4 } & $N$ & $\%$ \\
\hline $\begin{array}{l}\text { ARToolkit(12), FLARToolkit(1), FLARManager(1) } \\
\text { vb. }\end{array}$ & 14 & 41,13 \\
\hline osgART & 2 & 5.9 \\
\hline ARTag & 1 & 2.9 \\
\hline Droid AR & 1 & 2.9 \\
\hline Aurasma & 2 & 5.9 \\
\hline OpenCV + computer vision (CV) & 1 & 2.9 \\
\hline Ogre 3D framework+ computer vision (CV) & 1 & 2.9 \\
\hline ART capture & 1 & 2.9 \\
\hline Popcode & 1 & 2.9 \\
\hline in-house AR software library & 2 & 5.9 \\
\hline Location Global Positioning System (GPS) & 2 & 5.9 \\
\hline Google Glass Glass Development Kit(GDK) & 1 & 2.9 \\
\hline Vuforia & 3 & 8.8 \\
\hline Belirtilmemiş & 2 & 5.9 \\
\hline & 34 & 100 \\
\hline
\end{tabular}

Tablo 11, incelenen AG çalışmalarında kullanılan AG araç dağılımlarını yansıtmaktadır. Tablo incelendiğinde AG araç seçiminde büyük oranda açık kaynak kod tabanlı ARToolKit ve ailesine ait SDK paketlerinin $(\mathrm{N}=14$, \%41,13) kullanıldı̆̆ 
paketi, 2 yayın ile Aurasma, in-house AR Software Library, GPS, ARToolKit ve OpenSceneGraph temelli osgART SDK paketlerinin takip ettiği anlaşılmaktadır. Diğer SDK paketlerinin her biri 1'er yayında kullanılmıştır. İncelenen 34 çalışma içinde AG özelliğinin ne şekilde verildiği belirtilmemiş $(\mathrm{N}=2, \% 5,9)$ yayın sayısı 2 olarak görülmektedir.

\section{6. İNCELENEN AKADEMIK ÇALIŞMALAR IÇERISINDE DİKKAT ÇEKEN ARTIRILMIŞ GERÇEKLIK UYGULAMALARI (AUGMENTED REALITY APPLICATIONS IN ACADEMIC STUDIES)}

$\mathrm{Bu}$ kısımda, incelenen akademik çalışmalar içerisinde dikkat çeken AG uygulamaları seçilmiş ve bu uygulamaların özellikleri açıklanmaya çalışılmıştır. Ayrıca, burada yer verilen akademik çalıșmalardan bazıları İçten ve Bal'ın (2017) [1] makalesinde daha ayrıntılı bir şekilde ele alınıp incelenmiştir.

Insan Bilimi alanında; Mau-Tsuen Yang ve Wan-Che Liao (2014) [66] VECAR (Virtual English Classroom AR) isimli işaretçi tabanlı olmayan AG (ITOAG) yapısına sahip bir öneri çalışması yapmışlardır. Çalışmada işaretçi yerine açık kaynak kod tabanlı OpenCV Kütüphanesinin kameradan aldığg el hareketi kullanılmıştır. Kamera tarafindan alınan serbest el işaretinin durumu, konumu ve hareketi ekranda gösterilecek üç boyutlu (3D) nesnenin gösterilmesi, dönmesi ve boyut değiştirmesi gibi işlemlerin yapılmasını sağlamaktadır. Çalışmada PC, HMD, kamera ve projeksiyon gibi donanımların kullanıldığı görülmektedir. $\mathrm{Bu}$ uygulamaya ait ekran görüntüleri Şekil 7'de verilmiştir.
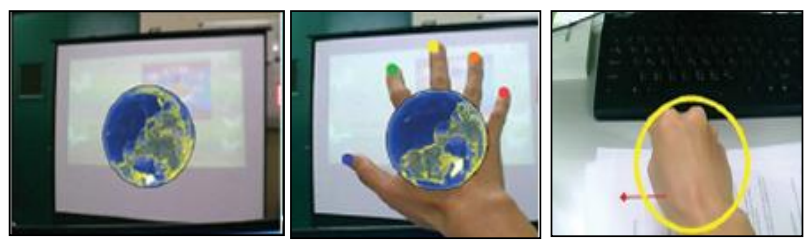

Şekil 7. VECAR

Doğal Afet ve Nükleer Kazalardan Korunma alanında; Tsai, Liu ve Yau (2013) [67] tarafindan konum (lokasyon) tabanlı AG teknolojisine sahip bir uygulama geliştirilmiştir. Çalışma deprem, doğal afet, terör ve nükleer kaza gibi durumlar da kullanıcıları en kısa zamanda en yakın sığınağa yönlendirmeyi amaçlamaktadır. Uygulama internete bağlı GPS bağlantılı akıllı bir telefon ile çalışmakta, kullanıcı ile olan etkileşimini dokunma, bilgilendirme ișlemini metin ve görsel resimler ile sağlamaktadır. $\mathrm{Bu}$ uygulamaya ait ekran görüntüsü Şekil 8'de verilmiştir.

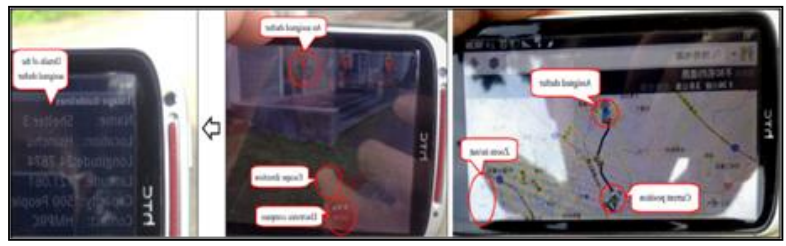

Şekil 8. AR-Based

Fen Bilimleri alanında; N. Enyedy ve ark. (2012) [68] fizik dersine yönelik $A G$ ve hareket yakalama teknolojisine sahip LLP (The Learning Physics Through Play Project) programı yapmışlardır. Şekil 9' da görüleceği gibi uygulama öğrenci hareketlerinin yakalanabilmesi için sınıf tavanına takılmış projeksiyon cihazı, hareketlerin öğrenci tarafindan izlenebilmesi için AG video görüntü ekranı, yapılan işlemleri sanal olarak gösteren projeksiyon perdesi, PC ve öğrenci tarafindan taşınan işaretçi gibi donanımlardan oluşmaktadır. Çalışma sonucunda AG teknolojisinin etkili bir öğrenme arac1 olduğu belirtilmiştir.

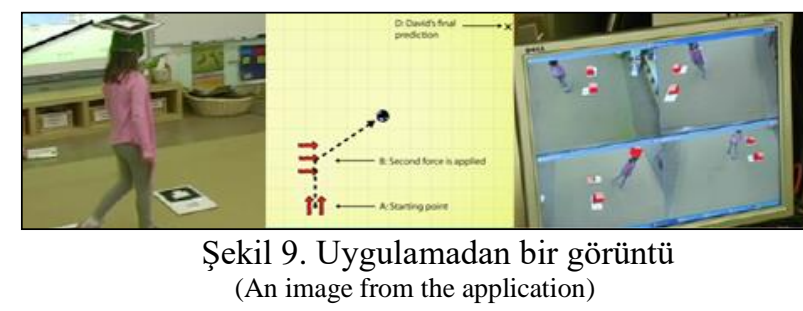

Ĕgitim alanında; Pérez-López ve Contero (2013) [69] tarafından sindirim ve dolaşım sistemi organlarının 3 boyutlu (3D) görüntüler şeklinde kullanıcı ekranında gösterilmesini sağlayan bir yazılım geliştirilmiştir. İşaret tabanlı AG teknolojisinin kullanıldığı çalışmada uzamsal görüntüleme sistemi olarak PC ve WebCam cihazı, etkileşim yöntemi olarak fare ve klavye kullanılmıştır. Uygulama ekranı üzerinde bulunan butonun tıklanması ile o butona ait 3 boyutlu (3D) görüntü kare işaretçi üzerinde, açıklayıcı metin ise ekranın altında gösterilmektedir. Şekil 10 'da ekran görüntüleri verilen sistemin oluşturulmasında Conitec Gamestudio Pro A7 programı kullanılmıştır

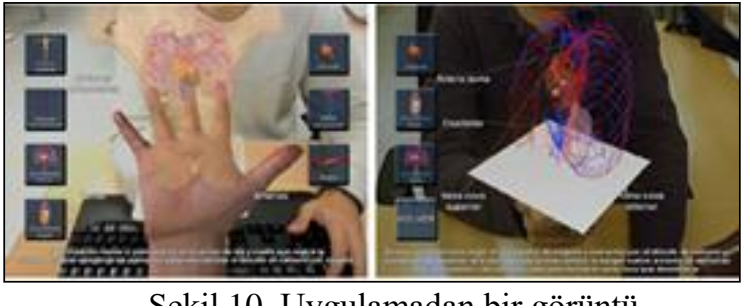

Şekil 10. Uygulamadan bir görüntü (An image from the application)

Ĕgitim alanında; S. Cuendet, Q. Bonnard, S. Do-Lenh ve P. Dillenbourg (2013) [70] tarafindan TinkerLamp, Tapacarp ve Kaleidoscope olarak isimlendirilmiş, sınıf ortamında kullanılabilen AG özelliğine sahip üç öğrenme ortamı için üç donanım sistemi tasarlanmıştır. Her üç öğrenme ortamı ARTag işaretçi yapısına benzer referans işaretçi kullanmaktadır. PC, WebCam, projeksiyon, 
kartlar, bloklar, etkinlik kitapçığı, kâğıt ve çizim araçları gibi materyallerin kullanıldığı çalışma kullanıcıya çizim derslerindeki 2 boyutlu (2D) görüntülerin 3 boyutlu (3D) görüntüler şeklinde gösterilmesini sağlamaktadır. Şekil 11 'de çalışmanın donanım, materyal ve işaretçilerin görselleri verilmiştir.
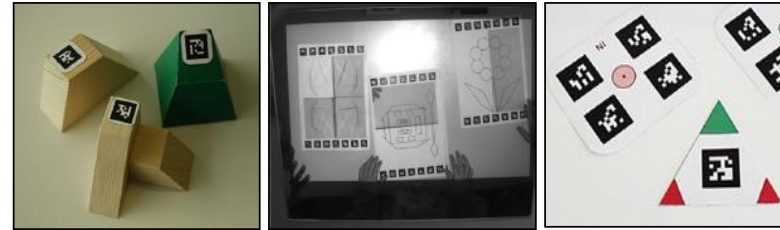

Şekil 11. TinkerLamp, Tapacarp, Kaleidoscope

Ĕgitim alanında; Abdüsselam ve Karal (2012) [71], fizik dersindeki "Manyetizma" konusunun öğretimi için artırılmış gerçeklik ortamı tasarlamışlar ve bu ortam kullanımının öğrenci akademik başarı üzerine etkisini incelemeye çalışmışlardır. 3 deney grubundan biri olan AG deney grubu için geliştirilen cihaz açık kaynak kod yapısına sahip mikro denetleyici Arduino geliştirme kartıdır. Çalışmada kare işaretçi (ITAG) yapısının kullanıldığı, çalışma ile kullanıcı arasındaki etkileşim yönteminin bilgisayara bağlanmış Arduino geliştirme kartına yaklaştırılan mıknatıs ve PC ekranındaki butonlar ile sağlandığı belirlenmiştir. Şekil 12'de çalışmadan alınmış örnek ekran görüntüleri yer almaktadır.
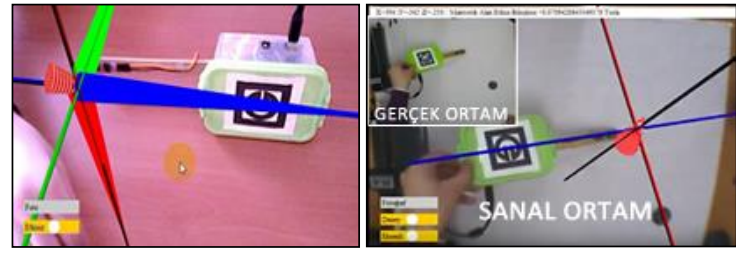

Şekil 12. Uygulamadan bir görüntü (An image from the application)

Ĕgitim alanında; İbili ve Şahin (2013) [72] 6. Sinıf matematik ders kitabındaki geometrik cisimler ünitesindeki 2 boyutlu (2D) statik görüntülerin 3 boyutlu (3D) görüntüler şeklinde bilgisayar ekranında görülmesini sağlayan, masaüstü bilgisayarlarda çalışabilen ARGE3D isimli bir yazılım geliştirmişlerdir. Şekil 13'de uzamsal görüntüleme sistem yapısına sahip bu çalıșmadan alınmış örnek ekran görüntüleri yer almaktadır. ARGE3D yazılımı için Visual Studio 2012, Microsoft Silverlight yazılım geliştirme düzlemi, SLARToolKit kütüphanesi, 3D görüntülerde Balder ve 3DS Max program1 kullanılmıștır. Bu çalışmada uzamsal görüntüleme sistemi olarak masaüstü bilgisayar (PC) ve WebCam ikilisi, işaretçi yapısı olarak beyaz kenarlık ile çevrelenmiş siyah zemin içine beyaz desenlerle resmedilmiş bir küp tercih edilmiştir.

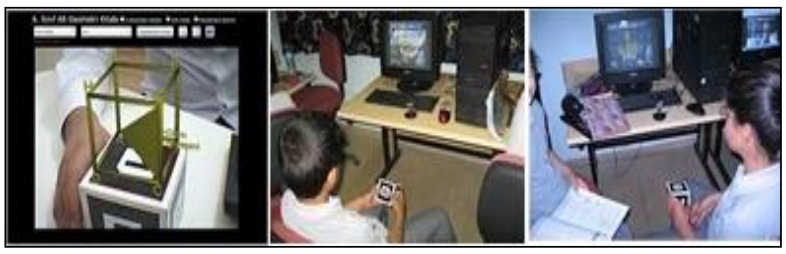

Şekil 13. Uygulamadan bir görüntü (An image from the application)

Mühendislik alanında; D. Parmar ve ark. (2015) [73] tarafından mühendislik alanında yer alan öğrencilerin grafik teknik bilgisini artırmaya yönelik bir uygulama çalışması yapılmıştır. Uygulama masaüstü bilgisayarların tüm işletim sistemlerinde ve android tabanlı tüm mobil araçlarda siyah beyaz desenli taşınabilir bir işaretçi ile kullanılabilmektir. Uygulama için AR-Book kitabı tasarlanmıştır. Şekil 14'de görüleceği gibi uygulama aşamasında AR-Book ve taşınabilir işaretçi kamera görüş açısına bırakılmalıdır. AR-Book kitap sayfası kullanıcı tarafından değiştirildikçe kitap sayfasında yer alan işaretçi yapısına göre çağrılan dijital 3D nesne taşınabilir işaretçi üzerine yüklenir ve ekranda görüntülenir.

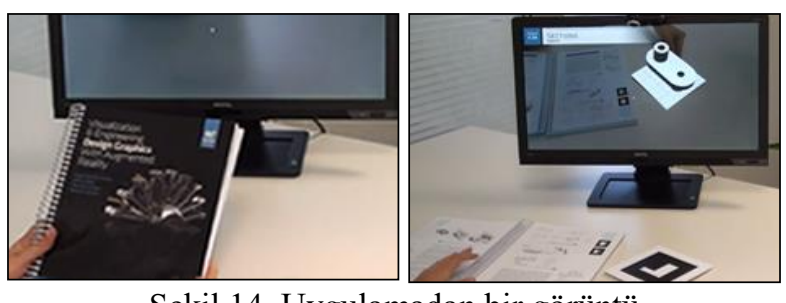

Şekil 14. Uygulamadan bir görüntü (An image from the application)

Trafik alanında; M. Zhang (2016) [74] tarafindan artırılmış gerçeklik teknolojisine sahip gerçek zamanlı trafik akış tahmin uygulaması yapılmıştır. Taşınabilir cihazlarda çalıştırılacak bu çalışma temel nesnelerin modellenmesinde (yol, ağaç, bina, bulut) Unity3D oyun motoru, modellemelerde AutoCAD ve 3DMax, model görevlerinde komut dosyaları (Scripts), kullanıcı ile çalışma arasındaki etkileşimde sanal ekran butonları kullanılmıştır. Şekil 15'de görüleceği gibi kullanıcının ekran butonlarındaki seçimine göre uygulamadaki yol, hava ve araç durumları değişecektir.
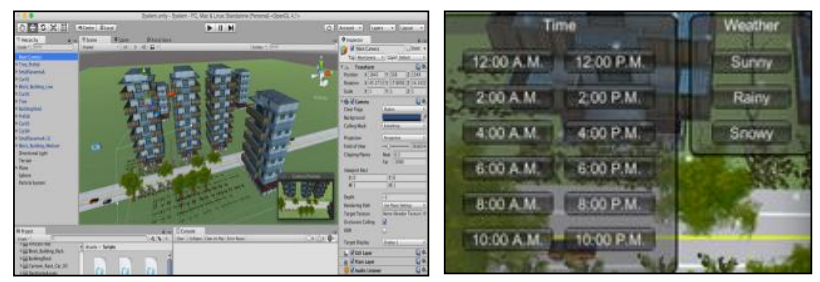

Şekil 15. Trafik AR (Traffic-AR)

Engelliler alanında; N. M. N. Zainuddin ve ark. (2010) [75] tarafında duyma engeli öğrencilerin kullanımına yönelik bir AG uygulama yazılımı (AR-Book) gerçekleştirilmiştir. AR-Book siyah beyaz işaretçi, PC ve WebCam araçları kullanılmaktadır. Görsel odaklı bir yapıya sahip AR-Book yazılımı 3 duyma engelli öğrenci 
üzerinde çalışması yapılmıştır. Uygulamaya “3D Model Marker" ve "İşaret Dili Marker" olmak üzere iki işaretçinin tanıtılması, "mikroskop" ders konusunun belirlenmesi ve AR-Book 1, AR-Book 2, AR-Book 3 kitapçıklarının tasarlanması yapılmıştır. Uygulama sonucunda işaretçi yapılı dijital 3D kullanımın rakiplerine göre daha başarılı olduğu belirtilmektedir. $\mathrm{Bu}$ uygulamaya ait ekran görüntüleri şekil 16 'da verilmiştir.

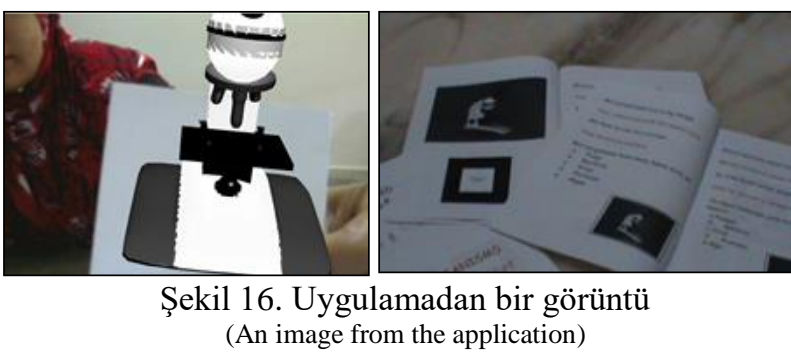

7. TARTIŞMA, SONUÇ VE ÖNERILLER (DISCUSSION, RESULTS AND RECOMMENDATIONS)

$\mathrm{Bu}$ çalışmada, artırılmış gerçeklik teknolojisine sahip ulusal ve uluslararası 34 akademik çalışma, yayım yılları, yayım yerleri, AG türleri, görüntüleme sistem türleri, kullanıcı ve cihaz etkileşim şekilleri ve kullandıkları AG araçları (fireworks) açısından incelenmiştir.

Çalışmada, belirlenen yıllar arasında en az çalışmanın 2010 ve 2011 yıllarında yapılmış olduğu, devam eden yıllarda $(\% 11,8-\% 20,6)$ birbirine yakın değerler olsa da $2010(\% 8,8)$ ve 2011(\%5,9) yıllarına göre az bir artışın gerçekleştiği görülmüştür. $\mathrm{Bu}$ artış sebebi; $\mathrm{AG}$ ortamlarının üzerinde çalıştığı cihaz teknolojisinin zamana bağlı olarak gelişimi, bilgiye erişimin kolaylaşması, araştırmacıların bu teknolojiye olan ilgilerinin artması ve uygulama alanının genişlemesi olarak söylenebilir. Bu artış ve değișim değerlerinin sebeplerini daha net açıklayabilmek için çalışmalarda araştırmaya dâhil edilen örneklem sayılarının çoğaltılması, zaman aralığının uzun tutulması gerektiğini ortaya çıkartmaktadır.

Çalışmada, incelenen 34 çalışmanın 27 farklı kaynakta yayınlandığı görülmüştür. 2010-2016 yılları arasında en çok çalışmanın IEEE'de yayınlandığı $(\% 17,6)$, bunu Computer\&Education $(\% 5,9)$ ve Procedia $(\% 5,9)$ 'nın takip ettiği, diğer 24 dergi veya kitapta 1 'er çalışmanın yayınlandığı belirlenmiştir. IEEE (eng: Institute of Electrical and Electronics Engineers)'de yayınlanan çalışma sayısının diğer dergi veya kitap yayın sayılarına göre oldukça fazla olması, bu derginin teknolojinin ilerlemesi için oluşturulmuş dünyanın en büyük profesyonel organizasyon yayını olmasından kaynaklandığı düşünülmektedir. Ayrıca bu yayın sayısı, IEEE'nin dünyada elektrik, elektronik, bilgisayar ve otomasyon teknolojilerindeki yayınlarının büyük bir bölümünü yayınlıyor olması ve farklı alanlarda yapılmış AG çalışmalarının bu dergideki yayınlanma durumu ile açıklanabilmektedir.
İncelenen çalışmalarda çoğunlukla İTAG'nin ( $\mathrm{N}=28)$ tercih edildiği görülmüştür. $\mathrm{Bu}$ gözlemle birlikte bunu İTOAG $(\mathrm{N}=4)$ ve KTAG $(\mathrm{N}=2)$ takip etmiştir. İTAG'nin temeline bakıldığında 3D modelin ekranda uygun yere yerleştirilmesi ve sisteme önceden tanıtılması gerektiği görülür. Diğer artırılmış gerçeklik türlerine göre İTAG çalışma sayısının fazla olması, 1999 yılında açık kaynak kodlu ARToolKit yazılımının piyasaya çıkmasından, bu bağlamda yapılan yayınların artmasından ve farklı alanlardaki araştırmacıların bu yapıyı kullanmasından kaynaklandığı düşünülmektedir. Aynı zamanda Augment, Vuforia, Wikitude ve Kudan vb. AG geliştirme araçları da ITAG çalışmalarının artmasında önemli bir etken olarak sayılabilir. İTOAG'nin İTAG'ye göre az olmasına, yazılımcıların ortama işaretçi eklemek yerine ortamdaki mevcut fiziksel nesne veya nesneleri yazilımla takip etme, bu duruma göre işlem yapma ve kaliteli donanım bulundurma gibi zorlu durumlar sebep olarak gösterilebilir. KTAG'nin en az tercih edilen izleme türü olmas1, uygulamalarda Küresel Konumlama Sistemi (GPS) ve Kablosuz Yerel Alan Ağı (WLAN) gibi teknolojilerin kullanım zorunluklarından, seçilecek cihazlarda bu özellikleri sağlayacak donanım ihtiyaçlarından kaynaklandığı söylenebilir.

Çalışmada, AG görüntüleme sistemlerinden en fazla video tabanlı sistemlerin $(\% 94,1)$ tercih edildiği belirlenmiştir. $\mathrm{Bu}$ tercihe, video tabanlı sistemlerin, uzamsal görüntüleme sistemlerini ve taşınabilir görüntü sistemlerini içinde barındırması, optik tabanlı sistemlerde $(\% 5,9)$ AG görüntüsünün direk olarak kullanıcının göz hizasında oluşturulmasını sağlayacak HMD cihazlarının oluşturulma ve programlanma güçlüklerinin neden olduğu söylenebilir. Aynı zamanda Video tabanlı çalışmaların fazla olması, masaüstü ve dizüstü bilgisayarların uzun zamandır hayatımızda yer alması, araştırmacıların bu cihazları kullanmadaki olumlu yetenekleri gibi durumlarla da açıklanabilir.

İncelenen araştırma sonuçlarına göre uzamsal görüntüleme sistemleri arasında en fazla PC ve WebCam ikilisin birlikte kullanıldığı, diğer donanım cihazlarını kullanan çalışma sayısının 1'er olduğu görülmüştür. Ancak belirtilen diğer cihazların bu iki donanımla kullanılmadığı anlamına gelmemektedir. Çalışmadaki bu fazlalığın sebebi; araştırmacıların çalışmalarında ek bir görüntü donanımına ihtiyaç duymamalarından kaynaklı olduğu düşünülmektedir. Çalışmaların sadece PC ve WebCam cihaz ikilisi kullanılarak yapılması araştırmacıların uygulamalarını WebCam bağlantılı masaüstü bilgisayarlarda veya taşınabilir cihazlarda (tablet\&telefon) gerçekleştirdikleriyle açıklanabilir. Bununla birlikte araştırmacıların çalışmalarında taşınabilir görüntüleme sistemlerinden tablet cihazları $(\% 77,8)$ mobil cihazlara $(\% 22,2)$ göre daha fazla tercih ettiği görülmüştür. Tablet cihazların tercih sebebi, 10 saate yaklaşan pil ömürleri, uygun satış fiyatları, yüksek seviyelerde kamera ve ekran çözünürlükleri ve en önemlisi ekran boyut büyüklüğü olarak açıklanabilir. Buna karşın incelenen araştırmalarda içinde sadece 2 tane 
3DGlass çalışmasının olduğu belirlenmiştir. Bunun sebebi olarak araştırmacıların video tabanlı sistemler üzerinde daha kolay ve esnek çalışma yaptığı, maliyetinin yüksek olması ve 3DGlass gibi cihazların çalışmayı sınırlandırmasını istemediklerinden kaynaklı olduğu düşünülmektedir.

Yapılan araştırmada AG çalışması ile kullanıcı arasında gerçekleşen etkileşim yönteminde en fazla Dokunma (\%25) ve Fare/Klavye (\%25) kullanımı olduğu belirlenmiştir. Bunu Ek Bir İşaretçi (\%17,5), Belirtilmemiş (\%15) takip etmektedir. En az sayının 3DGözlük $(\% 2,5)$ olduğu ortaya çıkmıştır. Dokunma ve Fare/Klavye kullanımını fazla olması, araştırmalarda daha önce belirtilen uzamsal ve taşınabilir sistemlerin sayılarının fazla olmasından kaynaklı olduğu düşünülmektedir. En az çalışmanın fiziksel buton ile yapılması araştırmalarda fiziksel buton etkileşiminin çok kullanışlı olmaması sebebiyle açıklanabilir. Open CV (\%5) ile yapılan çalışmaların az olması yine daha önce belirtilen ITOAG yapısındaki zorluklardan kaynakl olduğu düşünülmektedir.

Çalışmada, en fazla ARToolKit ve türevleri üzerine çalışma gerçekleştirildiği görülmüştür. $\mathrm{Bu}$ sonucun ARToolKit aracının açık kaynak ve İTAG tabanlı bir araç olmasından kaynaklı olduğu söylenebilir.

Bu doğrultuda aşağıdaki öneriler de ek olarak verilebilir;

- KTAG çalışmalarına daha fazla ağırlık verilebilir.

- Optik Görüntüleme Sistemleri üzerine fazla çalışmanın olmaması, gelecekte yapılacak çalışmalar için etkili bir uygulama alanı olabilir

- Ülkemizde ulusal araștırma kurumları tarafından AG sistemleri ve hareket algılamalı AG teknolojilerini içeren konular öncelikli alanlar listesine alınabilir, araştırmacıların bu alanlarda araştırma yapmaları teşvik edilebilir.

\section{KAYNAKLAR (REFERENCES)}

[1] T. İçten and G. Bal. "Artırılmış Gerçeklik Üzerine Son Gelişmelerin ve Uygulamaların İncelenmesi.", Gazi Üniversitesi Fen Bilimleri Dergisi Part C: Tasarım ve Teknoloji, 5(2), 111-136, 2017.

[2] P. Milgram, F. Kishino, "A taxonomy of mixed reality visua displays", IEICE Transactions on Information Systems, 77(12), 1321$1329,1994$.

[3] S.Somyürek, "Öğrenme sürecinde z kuşağının dikkatini çekmek: artırılmış gerçeklik”, Eğitim Teknolojisi Kuram ve Uygulama, 4(1), 63 $80,2014$.

[4] L. Koşan, "Muhasebe Eğitiminde Artırılmış Gerçeklik Uygulamaları", Çukurova Üniversitesi İktisadi ve İdari Bilimler Fakültesi Dergisi, 18(2), 2014.

[5] R. T. Azuma, “A Survey of Augmented Reality”, Teleoperatorsand Virtual Environments, 6(4), 355-385, 1997.
[6] Ç. Uluyol, "Bir Artırılmış Gerçeklik Uygulamasının Geliştirilmesi ve Öğrenci Görüşleri", Türkiye Sosyal Araştırmalar Dergisi, 3, 793-823, 2016

[7] Ç. Erbaş, V. Demirer, "Eğitimde Artırılmış Gerçeklik Uygulamaları: Google Glass Örneği”, Journal of Instructional Technologies \& Teacher Education, 3(2), 8-16, 2014.

[8] Y. Özarslan, “Öğrenen içerik etkileşiminin genişletilmiş gerçeklik ile zenginleştirilmesi”, 5. International Computer \& Instructional Technologies Symposium (ICITS 2011), Firat Üniversitesi, Elazı ̆̆, 726-730, 22-24 September 2011

[9] J. C. Gonzato, T. Arcila, B. Crespin, "Virtual objects on real oceans”, In Graphicon'2008, Russia, 49-54, 23-27 Jun, 2008

[10] S. C. Bronack, "The role of immersive media in online education.", The Journal of Continuing Higher Education, 59(2), 113$117,2011$.

[11] E. Klopfer, K. Squire, "Environmental detectives: the development of an augmented reality platform for environmental simulations.", Educational Technology Research and Development, 56(2), 203-228, 2008 .

[12] W. Zhu, C. B. Owen, H. Li, J. H. Lee, "Personalized in-store ecommerce with PromoPad: an augmented reality shopping assistant", Electronic Journal for E-commerce Tools and Applications, 1(3), 1-19, 2004.

[13] S. K. Feiner, "Augmented reality: A new way of seeing", Scientific American, 286(4), 48-55, 2002.

[14] D. W. F. Van Krevelen, R. Poelman, "A survey of augmented reality technologies, applications and limitations", International Journal of Virtual Reality, 9(2), 1, 2010.

[15] M. Sırakaya, S. S. Seferoğlu, "Öğrenme ortamlarında yeni bir araç: Bir eğitlence uygulaması olarak artırılmış gerçeklik.”, Eğitim Teknolojileri Okumaları 2016, Editör: A. İșman, F. Odabaşı, B. Akkoyunlu, Adapazarı: TOJET ve Sakarya Üniversitesi, 417-438, 2016.

[16] M. Billinghurst, H. Kato, I. Poupyrev, "The MagicBook - moving seamlessly between reality and virtuality", Computer Graphics and Applications, IEEE, 21(3), 6-8, 2001.

[17] L. Kerawalla, R. Luckin, S. Seljeflot, A Woolard, "Making it real: exploring the potential of augmented reality for teaching primary school science", Virtual Reality, 10(3-4), 163-174, 2006.

[18] T. P. Caudell, D. W. Mizell. "Augmented reality: An application of heads-up display technology to manual manufacturing processes." System Sciences, 1992. Proceedings of the Twenty-Fifth Hawaii International Conference, USA, IEEE, 659-669, 7-10 Jan, 1992.

[19] L. B. Rosenberg, "Virtual Fixtures: Perceptual Tools for Telerobotic Manipulation", Proceedings of IEEE Virtual Reality Annual International Symposium, 76-82, 1993.

[20] S. Feiner, B. Macintyre, D. Seligmann, "Knowledge-Based Augmented Reality", Communications of the ACM, 36(7), 53-62, 1993.

[21] R. Raskar, G. Welch, H. Fuchs, "Spatially Augmented Reality", First IEEE International Workshop on Augmented Reality (IWAR 98), San Francisco, 11-20, 1998.

[22] M. Fiala, "ARTag, An Improved Marker System Based on ARToolkit”, NRC, Canada, 2004 
[23] B. Thomas et al., "ARQuake: An outdoor/indoor augmented reality first person application", Wearable computers, the fourth international symposium on. IEEE, 139-146, 2000.

[24] C. Albanesius, "Google 'project glass' replaces the smartphone with glasses", PC magazine, 4, 2012.

[25] M. A. Livingston, Z. Ai, K. Karsch ve G. O. Gibson, "User interface design for military ar applications.", Virtual Reality (UK), 15(2-3), 175-184, 2011

[26] M. Yeh, C.D. Wickens, " Display signaling in augmented reality: Effects of cue reliability and image realism on attention allocation and trust calibration", Human Factors: The Journal of the Human Factors and Ergonomics Society, 43(3), 355-365, 2001.

[27] B. E. Shelton, N. R. Hedley, "Using augmented reality for teaching earth-sun relationships to undergraduate geography students." Augmented Reality Toolkit, The First IEEE International Workshop, Germany, 29 September, 2002.

[28] F. Liarokapis, P. Petridis, P. F. Lister \& M. White, "Multimedia augmented reality interface for e-learning (MARIE)", World Transactions on Engineering and Technology Education, 1(2), 173-176, 2002

[29] D. Wagner, T. Pintaric, F. Ledermann, D. Schmalstieg, "Towards massively multi-user augmented reality on handheld devices", Pervasive Computing: Third International Conference, Pervasive 2005, Berlin, 77-95, 8-13 May, 2005.

[30] A. Damala, M. Isabelle, H. Pascal, "Merging augmented reality based features in mobile multimedia museum guides." Anticipating the Future of the Cultural Past, CIPA Conference 2007, 1-6 October, 2007

[31] T. Sielhorst, T. Obst, R. Burgkart, R. Riener, N. Navab, "An augmented reality delivery simulator for medical training", International Workshop on Augmented Environments for Medical Imaging-MICCAI Satellite Workshop 2004, 7(6), 11-20, 2004.

[32] E. D. Pisano, H. Fuchs, A. State, M.A. Livingston, G. Hirotab, W F. Garrettb, M. C. Whitton, "Augmented reality applied to ultrasoundguided breast cyst aspiration", Breast disease, 10(3,4), 221-230, 1998.

[33] A. State, D. T. Chen, C. Tector, A. Brandt, H. Chen, R. Ohbuchi, M. Bajura ve H. Fuchs, "Observing a volume rendered fetus within a pregnant patient", Proceedings of the Conference on Visualization 94, Visualization'94, IEEE, USA, 21 October, 1994.

[34] V. V. Patel, M. W. Vannier, J. L. Marsh, L. Lo, "Assessing craniofacial surgical simulation", IEEE Computer Graphics and applications, 16(1), 46-54, 1996.

[35] R.H. Taylor, J. Funda, L. Joskowicz, A. D. Kalvin, S. H. Gomory, A. P. Gueziec, L. M. G. Brown, "An overview of computer-integrated surgery at the IBM Thomas J. Watson Research Center.", IBM journal of research and development, 40(2), 163-183, 1996.

[36] T. H. Höllerer, S. K. Feiner, "Mobile augmented reality", Telegeoinformatics: Location-Based Computing and Services, Editör: H. Karimi, A. Hammad, Taylor and Francis Books Ltd., London, UK 21, 2004

[37] V. Vlahakis ve ark., "ArcheoGuide: first results of an augmented reality, mobile computing system in cultural heritage sites", Proceedings of the 2001 conference on Virtual reality, archeology, and cultural Heritage, ACM, 131-140, 2001.

[38] V. Vlahakis, A. Demiris, E. Bounos, N. Ioannidis, "A nove approach to context-sensitive guided e-tours in cultural sites: Light augmented reality on PDAs", Proceedings of the 5th International conference on Virtual Reality, Archaeology and Intelligent Cultural Heritage. Eurographics Association, 57-66, 2004.

[39] T. H. J. Collett, B. A. MacDonald, "Augmented reality visualisation for player", In Proceedings of the 2006 IEEE International Conference on Robotics and Automation, ICRA 2006, 3954-3959, 2006

[40] K. Pentenrieder, C. Bade, F. Doil, P. Meier, "Augmented Realitybased factory planning - an application tailored to industrial needs", IEEE and ACM International Symposium on Mixed and Augmented Reality, Japan, 31-42, 13-16 Nov., 2007.

[41] A. Y. C. Nee, S. K. Ong, G. Chryssolouris, D. Mourtzis, "Augmented reality applications in design and manufacturing", CIRP Annals-Manufacturing Technology, 61(2), 657-679, 2012

[42] V. R. Kamat, S. E-Tawil, "Evaluation of augmented reality for rapid assessment of earthquake-induced building damage", Journal of computing in civil engineering, 21(5), 303-310, 2007.

[43] K. E. Chang, C. T. Chang, H. T. Hou, Y. T. Sung, H. L. Chao, C. M. Lee, "Development and behavioral pattern analysis of a mobile guide system with augmented reality for painting appreciation instruction in an art museum", Computers \& Education, 71, 185-197, 2014.

[44] P. Connolly, C. Chambers, E. Eagleson, D. Matthews, T. Rogers, "Augmented reality effectiveness in advertising", 65th Midyear Conference on Engineering Design Graphics Division of ASEE, 3-6, Oct., 2010.

[45] W. Piekarski, B. Thomas, "ARQuake: the outdoor augmented reality gaming system", Communications of the ACM,45(1), 36-38, 2002.

[46] H. L. Chi, S. C. Kang, X. Wang, "Research trends and opportunities of augmented reality applications in architecture, engineering, and construction", Automation in construction, 33, 116122,2013

[47] F. Roesner, T. Kohno, D. Molnar, "Security and privacy for augmented reality systems", Communications of the ACM, 57(4), 88-96, 2014

[48] W. R. Sherman, A. B. Craig, Understanding virtual reality: Interface, application and design, Elsevier, 2002

[49] H. Altınpulluk, "Artırılmış gerçekliği anlamak: kavramlar ve uygulamalar”, Açıöğretim Uygulamaları ve Araștırmaları Dergisi, 1(4), 123-13, 2015.

[50] M. A. Çakal, E. B. Eymirli, “Artırılmış Gerçeklik Teknolojisi”, Kuzeydoğu Anadolu Kalkınma Ajansı, http://www.kudaka.org.tr/ekler/fa254

artirilmis_gerceklik_teknolojisi.pdf, 10.08.2016.

[51] M. Fiala, "ARTag, an Improved Marker System Based on ARToolkit". National Research Council Canada, Publication Number: NRC, 2004

[52] A. T. Korucu, E. Usta, İ. F. Yavuzarslan, "Eğitimde Artırılmış Gerçeklik Teknolojilerinin Kullanımı: 2007-2016 Döneminde Türkiye'de Yapılan Araştırmaların İçerik Analizi", Alan Eğitimi Araştırmaları Dergisi, 2(2), 84-95, 2016

[53] A. Arslan, M. Elibol, "Analysis of educational augmented reality applications: The case of Android operating system Eğitsel artırılmı gerçeklik uygulamalarının incelenmesi: Android işletim sistemi örneği" Journal of Human Sciences, 12(2), 1792-1817, 2015. 
[54] Z. A. Yılmaz, V. Batdı, "Artırılmış Gerçeklik Uygulamalarının Eğitimle Bütünleştirilmesinin Meta-Analitik ve Tematik Karşılaştırmalı Analizi", Eğitim ve Bilim, 41(188), 2016.

[55] A. Yıldırım \& H. Şimşek, Sosyal bilimlerde nitel araştırma yöntemleri, Seçkin Yayıncılık, Ankara, 2006.

[56] A. Yıldırım \& H. Şimşek, Sosyal bilimlerde nitel araştırma yöntemleri, Ankara: Seçkin Yayınları, Ankara, 2008.

[57] K. Krippendorff, Content analysis: An introduction to its methodology, Beverly Hills: Sage, 2012.

[58] E Tavşancıl, E Aslan, İçerik analizi ve uygulama örnekleri, Epsilon yayıncılık, İstanbul, 2001.

[59] A. Koçak, A. Özgür, "İçerik analizi çalıșmalarında örneklem sorunu”, Selçuk Üniversitesi İletişim Fakültesi Akademik Dergisi, 4(3), 21-28, 2006

[60] K. H. Cheng ve C. C. Tsai, "Affordances of augmented reality in Science learning: Suggestions for future search", Journal of Science Education and Technology", 22(4), 449-462, 2013.

[61] E. İbili, Geometri dersi için artırılmış gerçeklik materyallerinin geliştirilmesi, uygulanması ve etkisinin değerlendirilmesi, Yayımlanmamış doktora tezi, Gazi Üniversitesi, Eğitim Bilimleri Enstitüsü, Ankara, 2013.

[62] M. Esengün, 2 Boyutlu Harita Ve Artırılmış Gerçeklik Tabanl Mobil Navigasyon Uygulamalarının Kıyaslamalı Değerlendirilmesi, Yüksek Lisans Tezi, İTU, Fen Bilimleri Enstitüsü, 2016.

[63] G. Cherchi, F. Sorrentino, R. Scateni, "AR Turn-by-turn Navigation in Small Urban Areas and Information Browsing", Eurographics Italian Chapter Conference, 37-40, 2014.

[64] R. Wojciechowski and W. Cellary, "Evaluation of learners" attitude toward learning in ARIES augmented reality environments." Computers \& Education, 68, 570-585, 2013.

[65] H. Fuchs and J. Ackerman, "Displays for augmented reality: Historical remarks and future prospects", Mixed Reality Merging Real and Virtual Worlds, Ohta Y and Tamura H, Ohmsha Ltd, 31-40, 1999.

[66] M. T. Yang, W. C. Liao, "Computer-Assisted Culture Learning in an Online Augmented Reality Environment Based on Free-Hand
Gesture Interaction", IEEE Transactions on Learning Technologies, 7(2), 107-117, 2014

[67] M.K. Tsai, P.H. E. Liu, N.J. Yau, "Using electronic maps and augmented reality-based training materials as escape guide lines for nuclear accidents: An explorative case study in Taiwan", British Journal of Educational Technology, 44(1), 2013.

[68] N. Enyedy, J. A. Danish, G. Delacruz, M. Kumar, "Learning physics through play in an augmented reality environment", International Journal of Computer-Supported Collaborative Learning, 7(3), 347-378, 2012.

[69] D. Pérez - López, M. Contero, "Delivering educational multimedia contents through an augmented reality application: A case study on its impact on knowledge acquisition and retention", The Turkish Online Journal of Educational Technology, 12 (4), 19 - 28, 2013.

[70] S. Cuendet, Q. Bonnard, S. Do-Lenh \& P. Dillenbourg, "Designing augmented reality for the classroom." Computers \& Education, $68557-$ $569,2013$.

[71] M. S. Abdüsselam, H. Karal, "Fizik öğretiminde artırılmış gerçeklik ortamlarının öğrenci akademik başarısı üzerine etkisi: 11. Sınıf manyetizma konusu", Ĕgitim ve Öğretim Araştırmaları Dergisi, 1(4), Makale 20, ISSN: 2146-9199, 170-182, Kasım 2012.

[72] E. İbili, S. Şahin, "Artırılmıș Gerçeklik ile İnteraktif 3D Geometri Kitabı Yazılımın Tasarımı ve Geliştirilmesi: ARGE3D”, Afyon Kocatepe Üniversitesi Fen ve Mühendislik Bilimleri Dergisi, 13(1), 1-8, 2013.

[73] D. Parmar, K. Pelmahale, R. Kothwade, P. Badgujar, "Augmented Reality System for Engineering Graphics", International Journal of Advanced Research in Computer and Communication Engineering (IJARCCE-), 4(10), 327-330, 2015.

[74] M. Zhang, Real-time traffic flow prediction using augmented reality, Yüksek Lisans Tezi, the University of Windsor, School of Computer Science, 2016.

[75] N. M. M. Zainuddin, H. B. Zaman, A. Ahmad, "A Participatory Design in Developing Prototype an Augmented Reality Book for Deaf Students", Second International Conference on Computer Research and Development, IEEEComputerSociety, 400-404, 2010. 